$$
\text { بملة جامعة أم درمان الاسلامية }
$$

\title{
https://journal.oiu.edu.sd/index.php/oiuj
}

\section{نشأة وتظور منظمات المجتمع المدني في المجتمع الإسلامي مقارنة بالغرب}

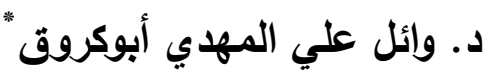

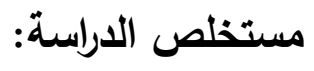

أن النظر إلى مسألة ما ينتج عادة عن أرتباط ما تطرحه تلاك المسألة، من مشكلات ترنبط فيما بينها ونتشابك، حيث يصعب نتاول واحدة منها دون النظر إلى بقية نظيراتها بالدرس والتحليل والتأسيس، فهو بالضبط ما يواجه الباحث عندما

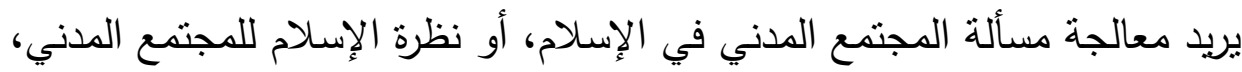

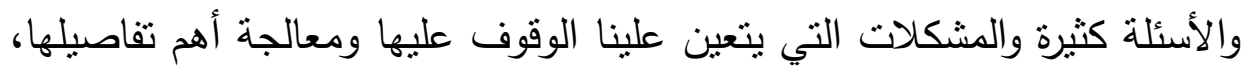

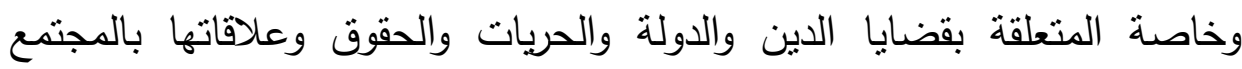

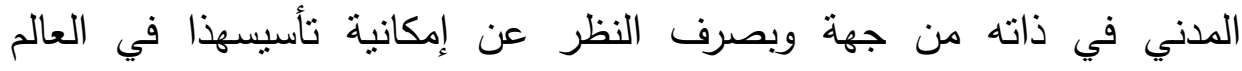

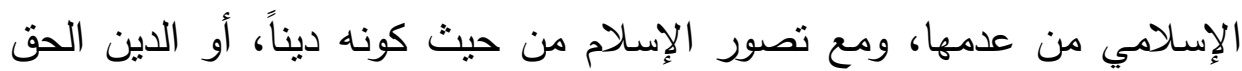
كتلك القضايا ذاتها ولهذه العلاقة نفسها من جهة ثنانية.

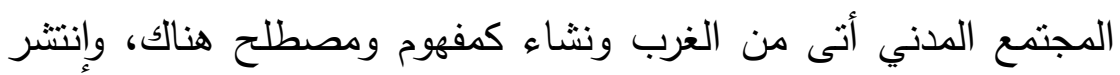

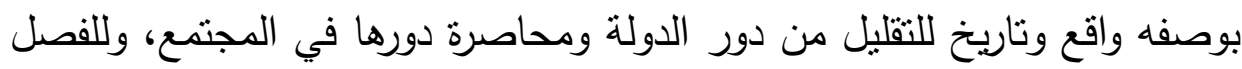
التام بينها وبين الدين أو بين السلطة المدنية والسلطة الدينية، لكي يتمكن من

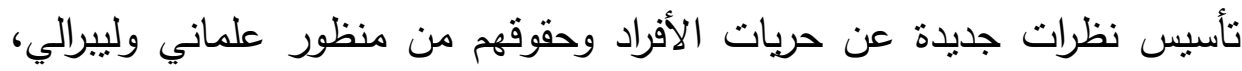
والدفاع المستميت عنها، ولتكريسها في المجتمع وتدعيمها بين مختلف مكوناته.

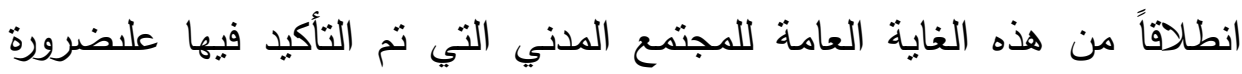

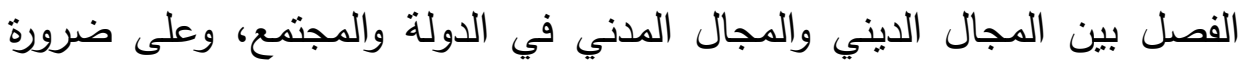

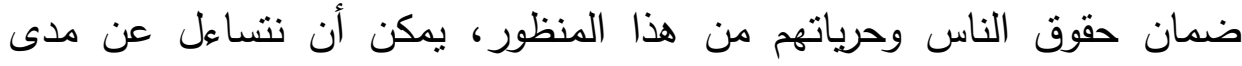

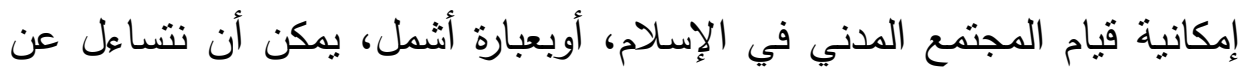

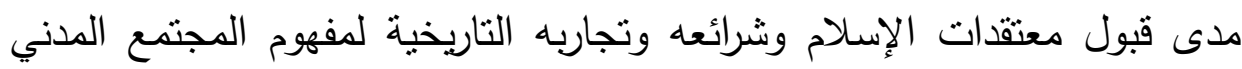


نشأة وتطور منظات الجمتع المدني في الجنمع الإسلاي مقارنة بالغرب - د. دوائل علي المهدي أبو كوق

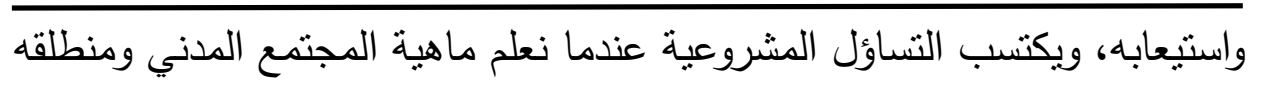
النظري والفكريومبادئه وقِيمه وتدبيره لأهدافه. فقد أستجابالتاريخ للتجربة الغربية في تدبير شؤون مجتمعاتها من منئه منظورها الفلسفي والسياسي للعلاقة بين الدين والسلطة، وفيما يتعلق بها من قضايا في حقوق الإنسان و حرياته: • كيف يمكن للإسلام أن يستوعب هذه الإنهان و لتجربة؟

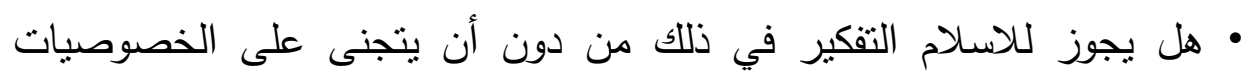

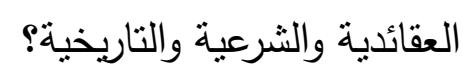

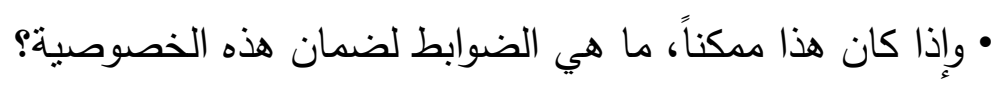

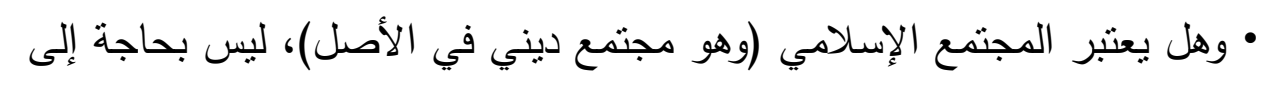

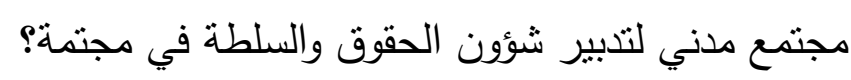

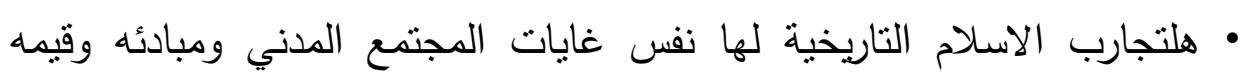

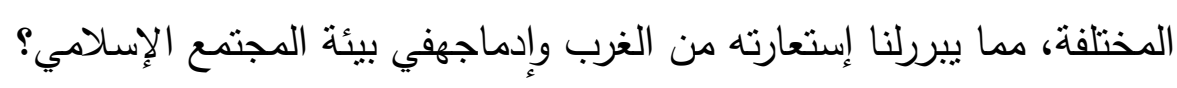

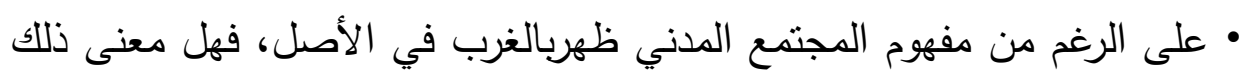

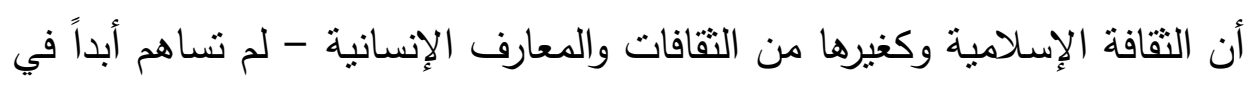

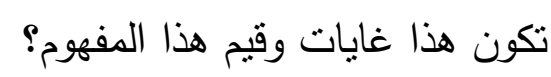
هذه الأسئلة نطرحها، لنعلنأطروحة محوريةاساسها أنه: إذكان المجتمع المدني في دلفي الغرب أنطلق من معالجة الغرب لفلسفة السياسة وعلم الإجتماع ولسؤال الدولة

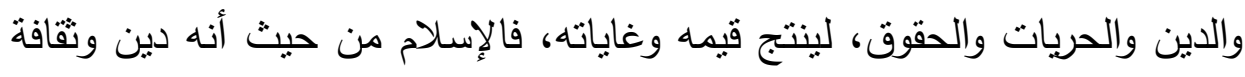

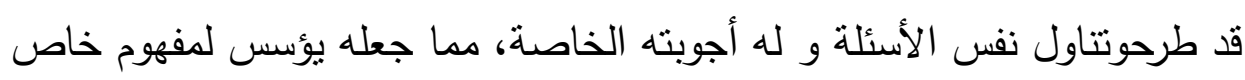

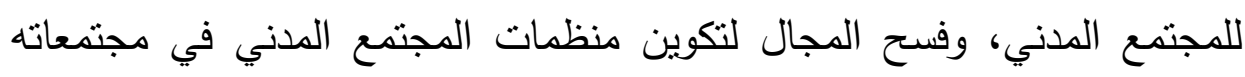
وبين أهله. 


\begin{abstract}
To look at the question of what is usually caused by the correlation of the problems posed by that issue, interrelated and interrelated, where it is difficult to address one of them without looking at the rest of their counterparts lesson, analysis and establishment, it is exactly what confronts the researcher when he wants to address the issue of civil society in Islam, or Islam's view of civil society, and the many questions and problems that we must stand on and address the most important details, especially on issues of religion and the state and freedoms and rights and their relations with civil society itself on the one hand and regardless of the possibility of establishing this in the Islamic world, or with the perception of Islam from the neighborhood $\mathrm{W}$ being a religion, or the right religion for those same issues and for this same relationship on the other hand.

Civil society came from the West and grew up as a concept and term there, and spread as a reality and history to reduce the role of the state and besieging its role in society, and to completely separate them from religion or between civil authority and religious authority, so that it can establish new views on the freedoms and rights of individuals from a secular and liberal perspective, And the desperate defense of them, and to consolidate them in society and strengthen them among the various components.

Based on this general purpose of civil society in which the need to separate the religious and civil spheres in the state and society, and the need to ensure the rights and freedoms of the people from this perspective, we can ask about the possibility of civil society in Islam, or more broadly, To question the extent to which the beliefs, laws, and historical experiences of Islam accept the concept of civil society and absorb it. The question arises legitimacy when we know what civil society is, its theoretical and intellectual standpoint, its principles, values and management of its objectives.

History has responded to the Western experience in managing the affairs of its societies from its philosophical and political perspective of the relationship between religion and power, and in relation to human rights and freedoms:

- How can Islam absorb this experience?

Is it permissible for Islam to think about this without prejudice to the ideological, legal and historical peculiarities?
\end{abstract}


نشأة وتطور منظطات المجتع المدني في المجتع الإسلامي مقارنة بالغرب - د. وائل علي المهدي أبو كروق

- If possible, what are the controls to ensure this privacy?

- Is the Islamic community (which is originally a religious community), does not need a civil society to manage the affairs of rights and power in a community?

- Do the historical experiences of Islam have the same goals, principles and different values of civil society, which justifies us borrowing it from the West and its integration into the environment of Islamic society?

- Although the concept of civil society originally appeared in the West, does this mean that Islamic culture, like all other cultures and human knowledge, never contributed to the goals and values of this concept?

We ask these questions, to declare a central thesis based on that: since the civil society in the West began from the West's treatment of the philosophy of politics and sociology and the question of the state, religion, freedoms and rights, to produce its values and goals, Islam in terms of religion and culture has raised and addressed the same questions and has its own answers, This established a special concept for civil society, and allowed for the formation of civil society organizations in his societies and among his people.

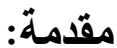

أن الإنسان في مبتدأ حياته عرف، قبل قيام الدولة، مؤسسات إجتماعية

تكافلية بسيطة تعينه على كسب عيشه، وحفظ نفسه، مندرجاً في هذا من الأسرة

إلى العثيرة ثم القبيلة، ومن القرية إلى المدينة ثم الدولة،تتميز هذه المؤسسات

بعفوية التكوين وحاجية الغايات. وكلما أرتقى المجتمع في مدارج التحضر تحول

في نظمه وتتظيماته من البساطة إلى التعقيد، ومن الفردانية إلى التنوع والتعدد،

ومن الإستقلالية إلى التداخل في شبكة تبادلية. فتتعدد الأهداف، وتتاغم حيناً،

وتتضاد في أحيان أخرى، ومن ثم تختلف طرائق تحقيق تلك الأهداف التي تتتوع

مجالاتها، إجتماعية وثقافية وتتموية، إقتصادية وسياسية(1).

1-سعد الدين إبراهيم، (مشرف عام)، دور وسائل الإعلام العربية في دعم ثقافة المجتمع نقات

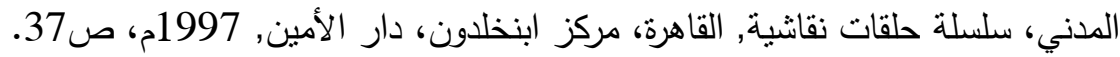


تختلف درجة هذه التحولات من مجتمع إلى آخر ، ومن بيئة إلى أخرى، ومن

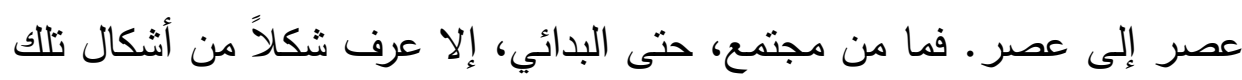

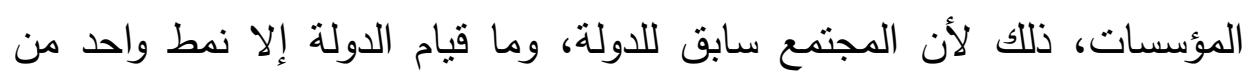

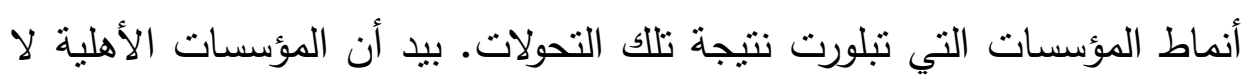

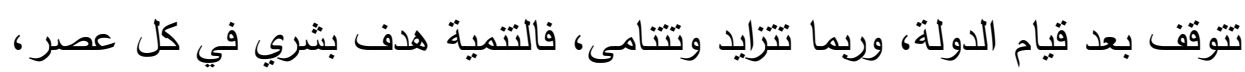

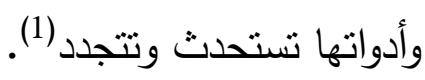
من هنا يتبدى أن مفهوم المجتمع المدني لا ينفصل عن أهدافه ووظائفه التي

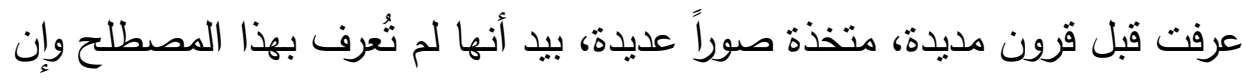

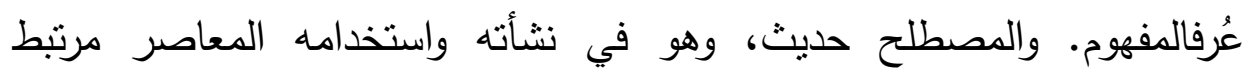
بالتجربة الغربية، وملتصق بثلاثة نظم، هي الليبرالية والرأسمالية والعلمانية

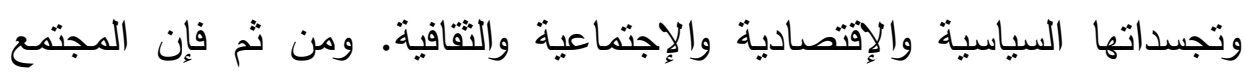
المدني نشأ من خلال الصراع الذي خاضته الطبقة المتوسطة (البرجوازية)

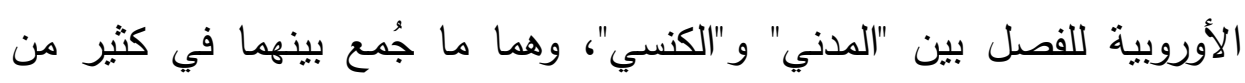
الحالات في التجربة الأوروبية. لقد كانت السلطة الزمنية والسلطة الدينية الدئة تتركزان

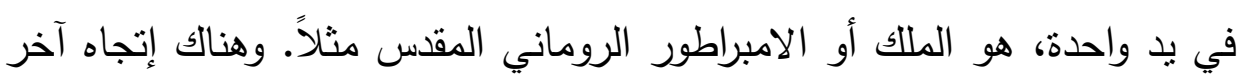

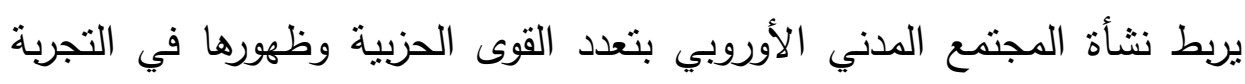

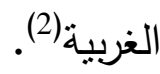
لعل من المفيد الإثارة إلى أن المفهوم السياسي لهصطلح المجتمع المدني ليس

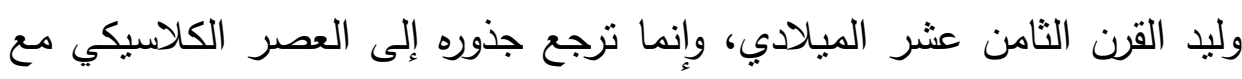
1- د.منعب مناف، لماذا المجتمع المدني، مجلة الحكمة، دار الحكمة، بغداد، العدد 361،

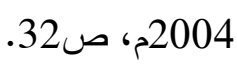
2 -حسن كاظم وعلي حاكم صالح، المجتمع الددني تاريخ نقدي، معهد الدراسات الاستراتيجية،

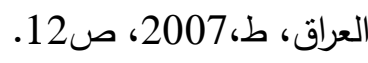


نشأة وتطور منظات الجنتع المدني في الجمتع الإسلاي مقارنة بالغرب - د. وائل علي المهدي أبو كروق

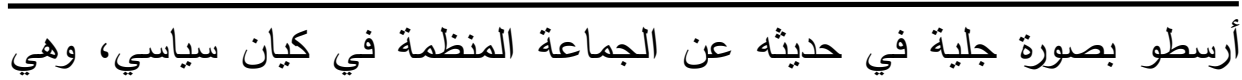

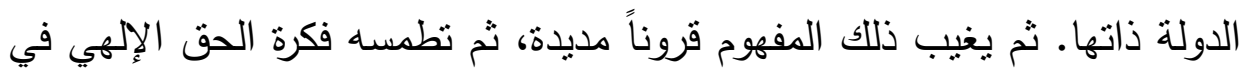
كتابات فلاسفة اللاهوت النصراني في العصور الوسطى. ثم مهذ لظهوره إنبعاث

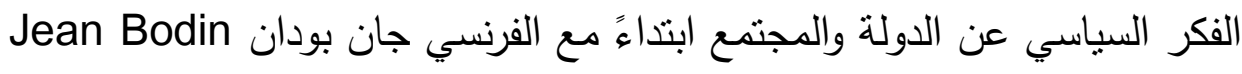

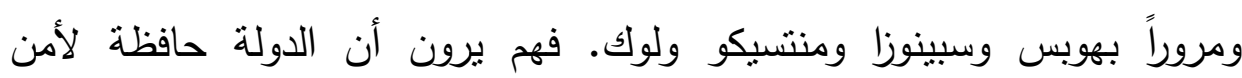

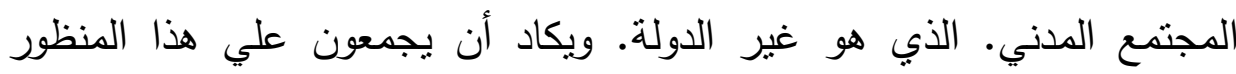

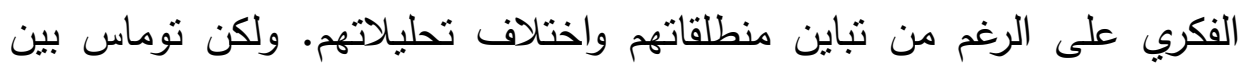
Thomas Paine

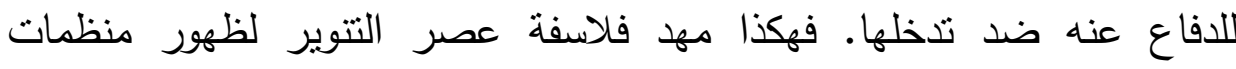

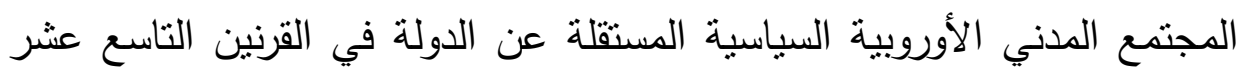
والعشرين الميلاديين (1).

\section{المبحث الأول}

\section{مفهوم المجتمع المدني: civilian society}

يُعتبر مفهوم المجتمع المدني من المفاهيم المتداولة بشكل واسع في الخطاب

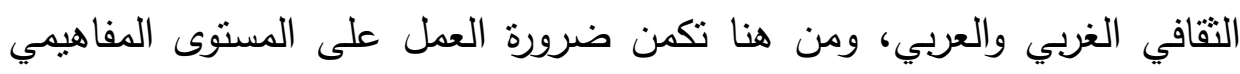

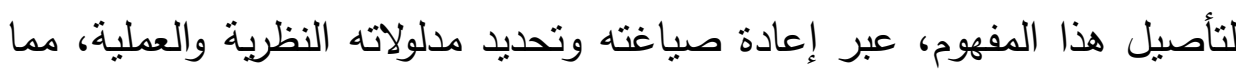

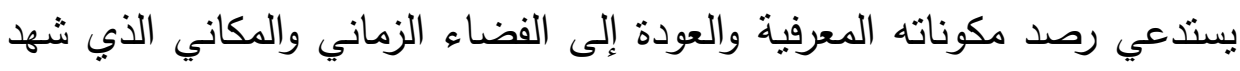

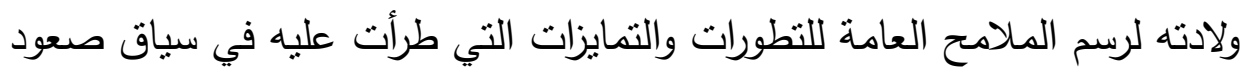

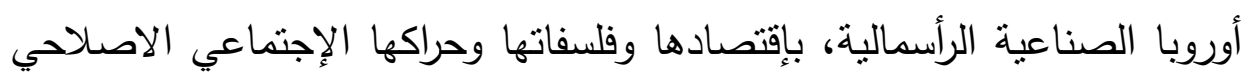

1 - د. كريم أبو حلاوة، إثكالية مفهوم المجتمع المدني: النشأة والتطور والتجليات، دمشق،

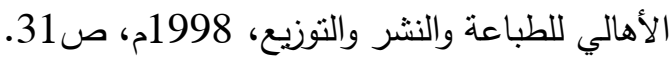


المتدرج والثوري التغييري، أي في جملة العوامل والأحداث التي ساهمت في تكريس

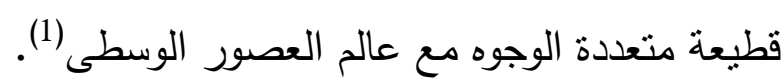
نظراً للطابع الإثكالي الذي ينطوي عليه مفهوم المجتمع المدني، بإعتباره تجريداً

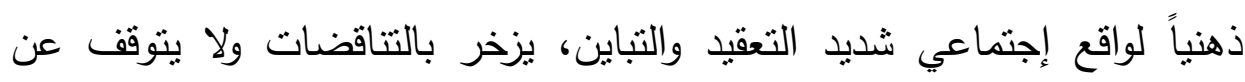

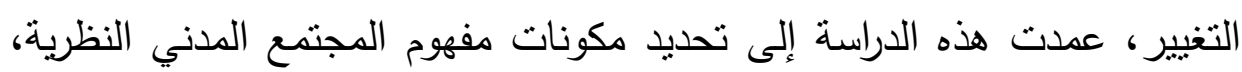

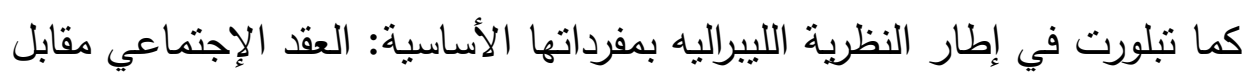

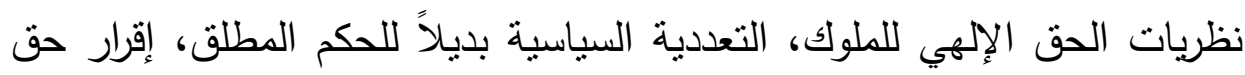

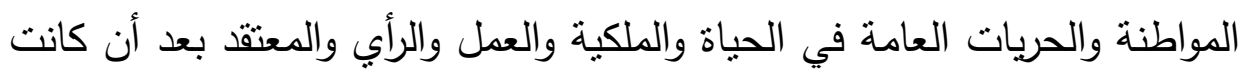

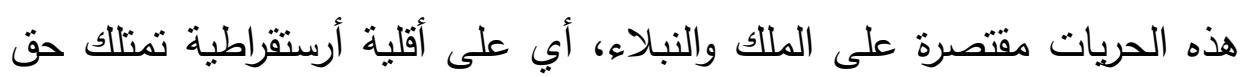

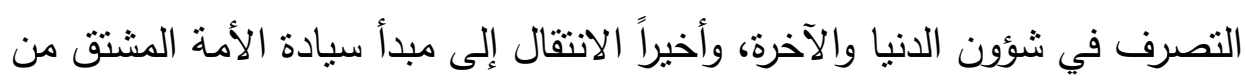

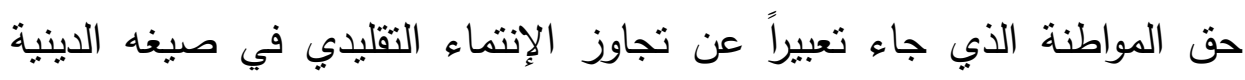

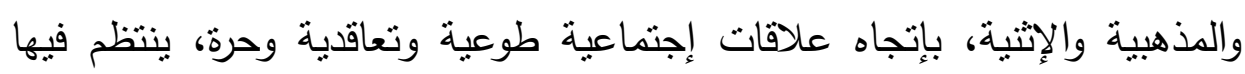

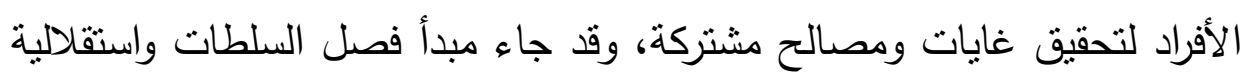

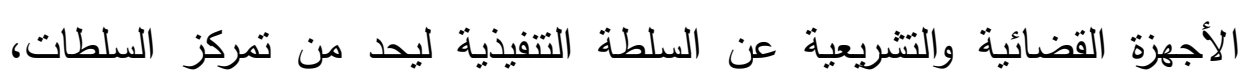
ويعيق إمكانية التحكم غير الثرعي في شؤون الدولة والمجتمع.

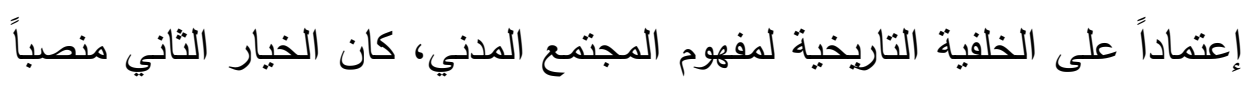

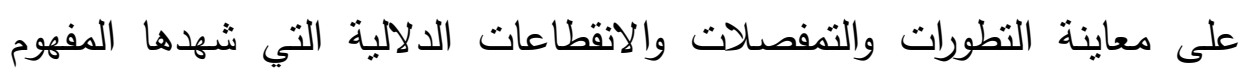
خلال تاريخه الطويل. وهذا ما يحيل على أهمية تقصي المنظومة الكفاهيمية التي

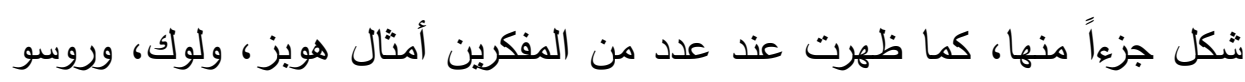

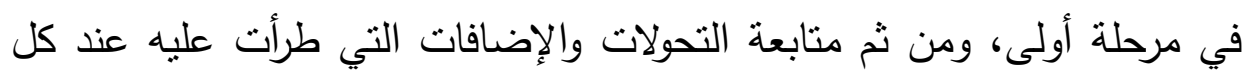

1- غازي الصوراني، التطور الناريخي لمفهوم المجتمع الددني والأزمة الاجتماعية في بلدان

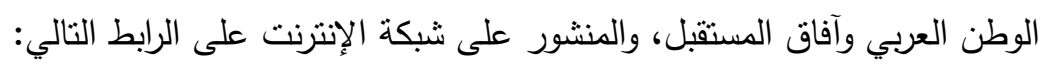
9489http://www.rezgar.com/debat/word.art.asp?aid= 
نشأة وتطور منظات الجمتع المدني في الجمتع الإسلاي مقارنة بالغرب - د. وائل علي المهدي أبو كووق من هيغل، وماركس، وغرامشي، والتوقق عند الرهانات النظرية، والتوظيفات

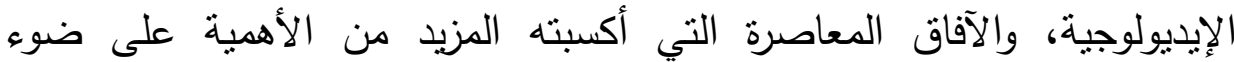
التغييرات والتحولات الكبرى التي شهدها العالم في السنوات القليلة الماضية. الحقيقة أنه بالرغم من الاجتهادات العديدة التي طرحت تعريفات لهذا المفهوم وحاولت تحديد نطاقه وأطرافه، إلا أن الخلافات بينها مازالت متعددة، يقينا أن هذه الخلافات في العديد من الأحيان ليست محض إختلافات في الدقة الأكاديمية للتعريف بقدر ما هي أنعكاس لإختلافات في الروية لطبيعة مفهوم المجتمع المدني لئي والدور المنوط به تحديداً (1). هناك من طرح المجتمع المدني بديلاً للدولة وهناك من طرحه مكملاً لدور الدولة،

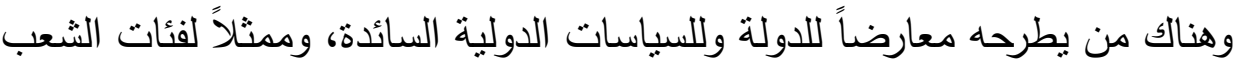

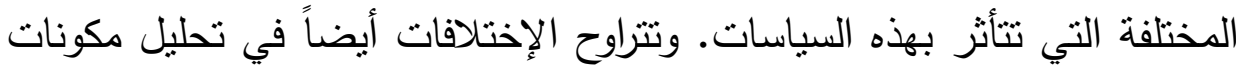
المجتمع المدني من حصره في المنظمات الأهلية، وهناك العديد من الذين

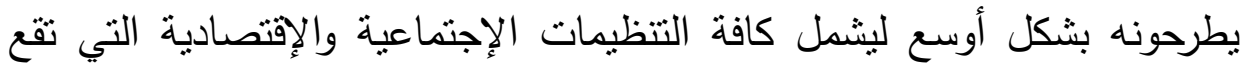

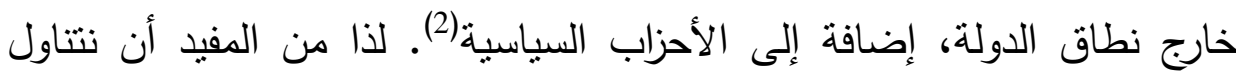
المحطات التاريخية للنطور الفكري لهذا للمفهوم، من أجل تتبع تطور الأفكار حوله الهابه

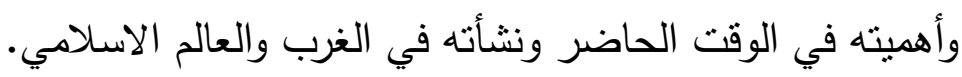

1 - برهان غليون، نشأة مفهوم المجتمع الددني وتطوره من الدفهوم الدجرد إلى الدنظومة الاجتماعية والدولية، وكانت محاضرة أُلَقتث بجامعة قطر ونشرتها مجلة أخبار الثرق على ثلى ثلاثة

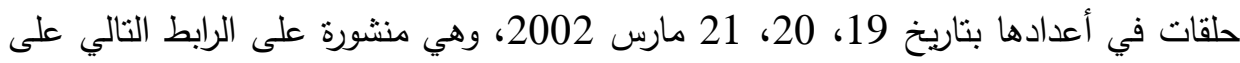

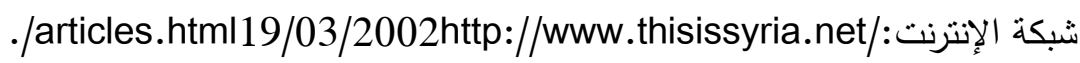
2-هشام جعفر، العمل الأهلي: رؤية إسلامية، على موقع الإسلام على الإنترنت أيضًا على الرئ الرابط: http://www.islamonline.net/Arabic/contemporary/2000/02/article57.shtml 
شهذ تعبير المجتمع المدني زيوعاً وانتشاراً هائلين في العقدين الأخيرين من القرن

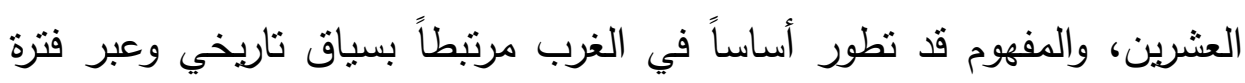

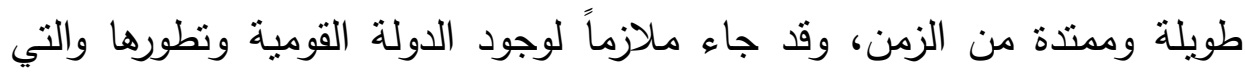

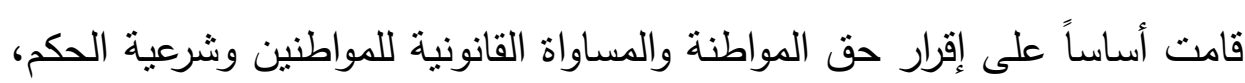

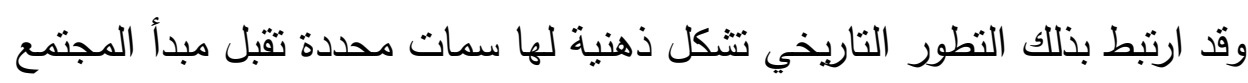

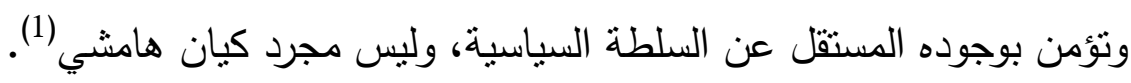

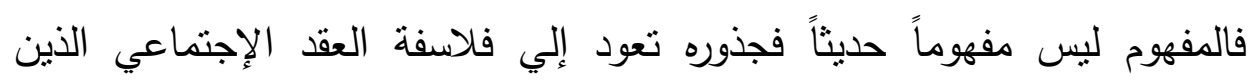

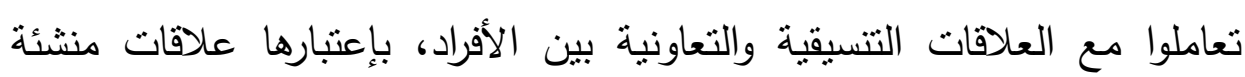

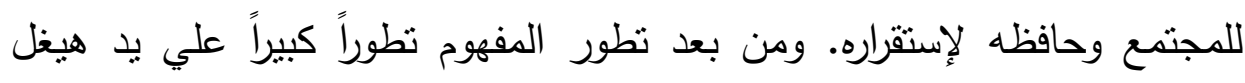
الذي ميز بين المجتمع المدني كثبكة من التفاعلات التلقائية القائمة علي العادات

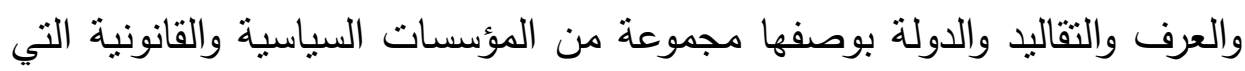
تُمارس في إطارها شبكة العلاقات السابقة0لكن رغم هذه الجذور التاريخية للمفهوم إلا أن أستخدامه بشكل مكثف في أدبيات السياسة المقارنة ارتبط بعقدي الثمانينات والتسعينات وما صحبهما من نطور في إتجاه الديمقراطية(2).

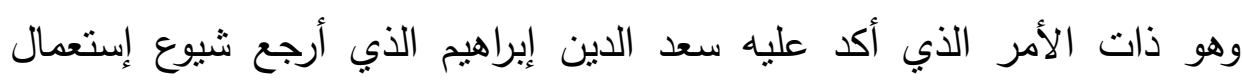

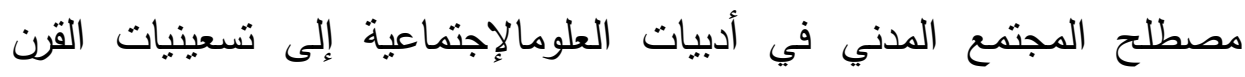
1- أماني قنديل، المجتمع المدني في مصر، في: نازلي معوض (تقديم وتحرير)، الخبرة

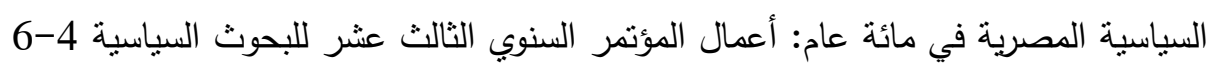

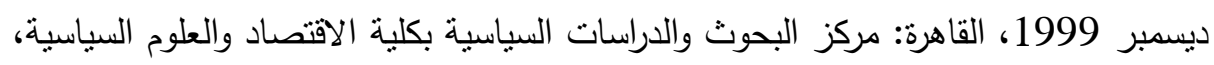

$$
\text { 2001م، ص } 263 .
$$

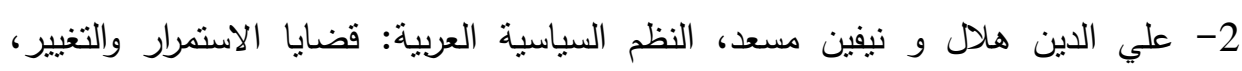
بيروت: مركز دراسات الوحدة العربية، الطبعة الأولى، لئل 2000م، ص صلية 178-180. 
نشأة وتطور منظات الجمتع المدني في الجنمع الإسلاي مقارنة بالغرب - د. دوائل علي المهدي أبو كوق

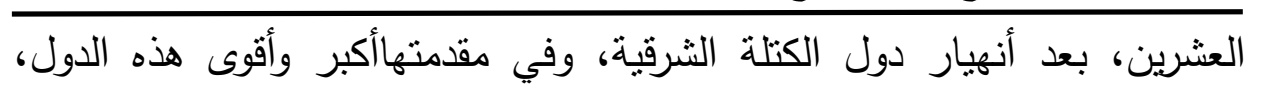

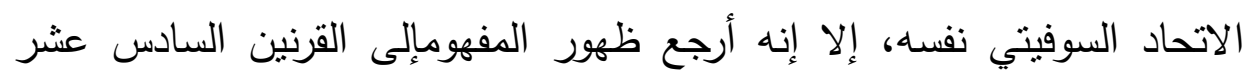

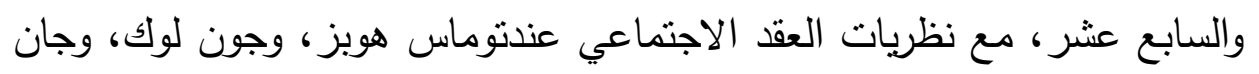

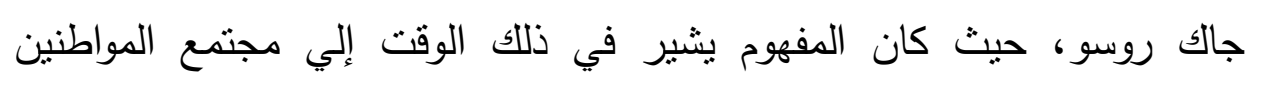

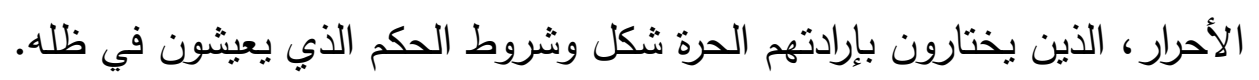

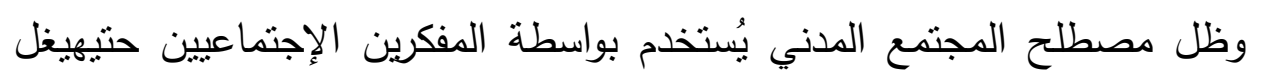
وماركس، أي إلي أواخر القرن التاسع عشر النّان.

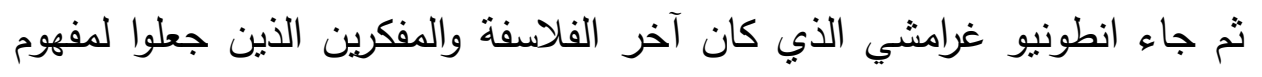

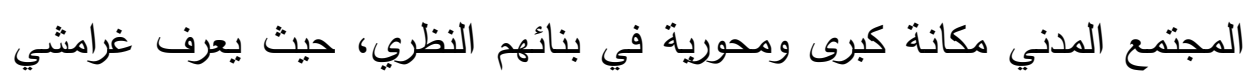
المجتمع المدني في سياق حديثه عن المنققين وتكوينهم، محدداً مستوبين للأبنية لئنية

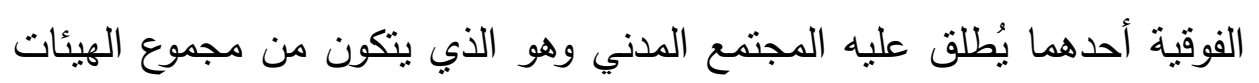

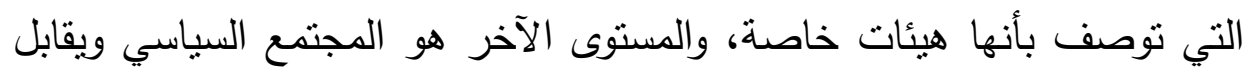

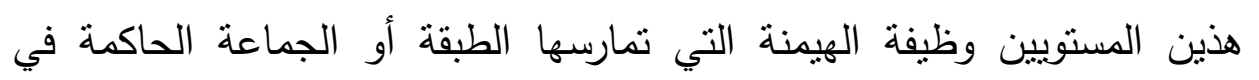

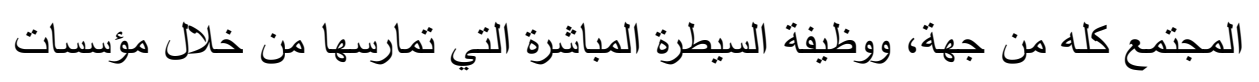

1- سعد الدين إبراهيم، الدثقفون العرب والتخريب الحالي لمصطلح المجتمع المدني، جريدة

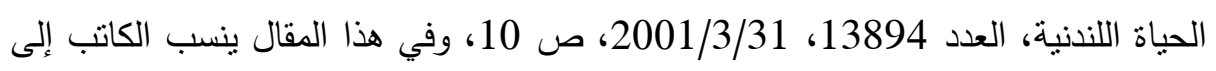

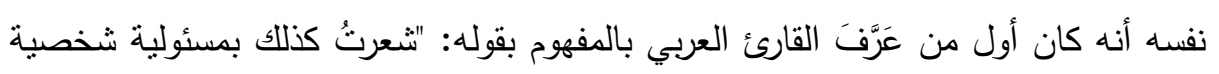

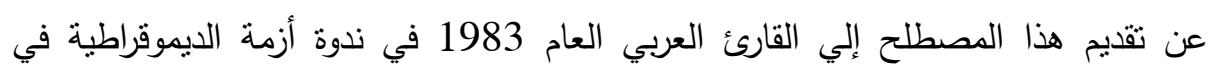

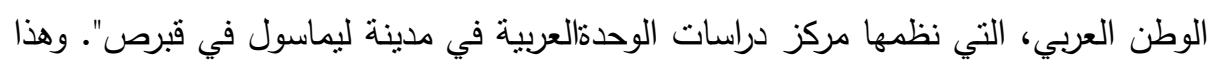

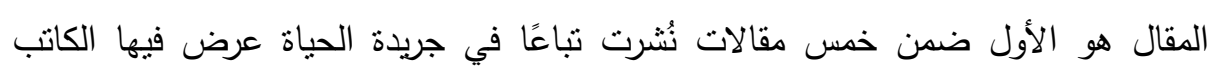

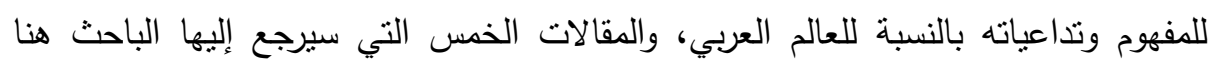

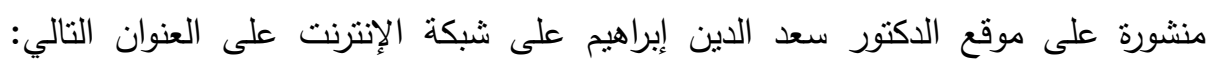
http://www.democracy-egypt.org/saadweb/articles.htm 
الدولة وحكم القانون من جهة أخرى. ومن ثمّ بعتبر غرامشي المجتمع المدني ذلك

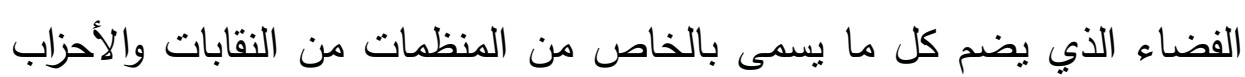

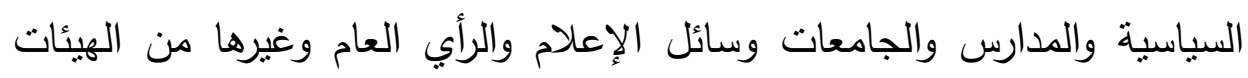

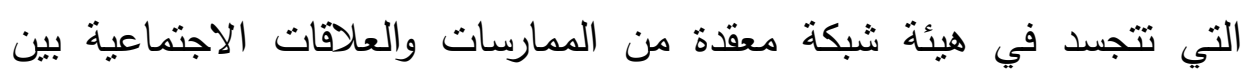
الأفراد(1)،كن غرامشي أكد في ذات الوقت فئن على عدم التكافؤ بين سلطة الدولة

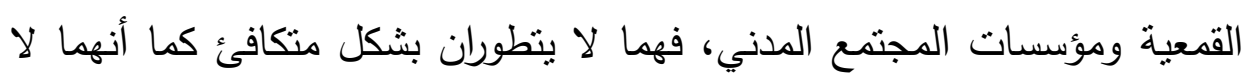

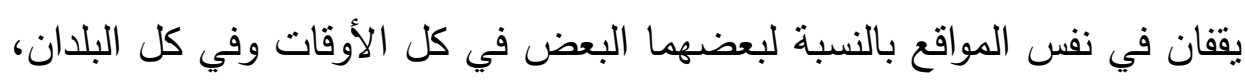

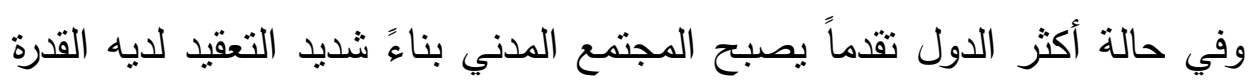

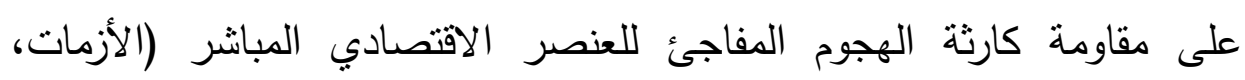
الكساد. إلخ) (2).

1- أحمد حسين حسن، الجماعات السياسية الإسلامية والمجتمع المدني، ( القاهرة: الدار

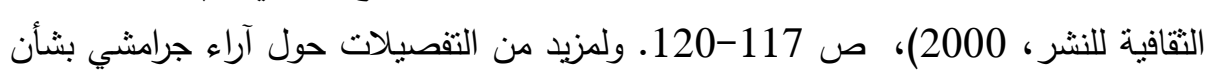
المجتمع المدني يمكن الرجوع بشكل تفصيلي إلى: برهان غليون، نشأة مفهوم المجتمع المدني

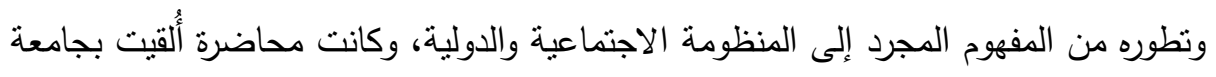

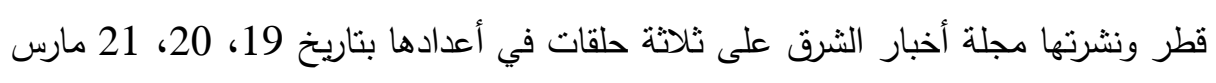

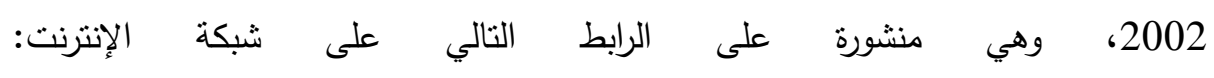

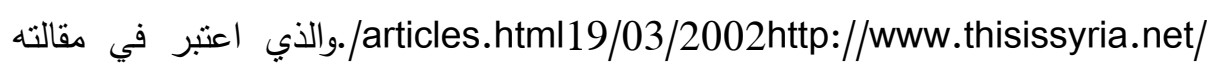
أن جرامشي هو الذي نرك أكبر الأثر على المفهوم كما يُستخدم اليوم، بعد استبعاد عناصر

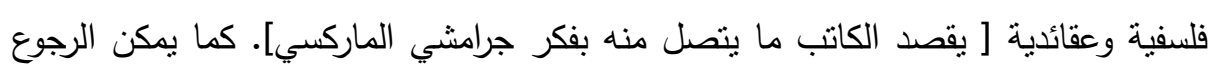

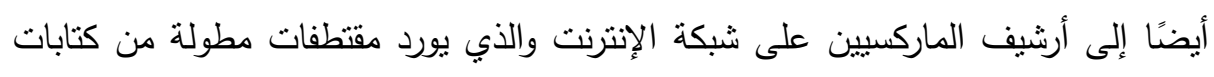

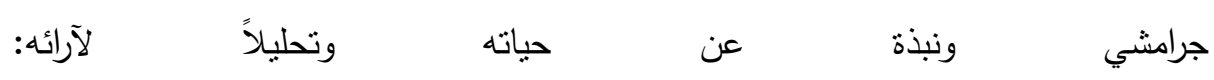
http://www.marxists.org/archive/gramsci/index.htm 2-جون مولينو، الماركسية والحزب، والذي جعل عنوان الفصل السادس منه والذي عرض فيه لفكر جرامشي: جرامشي والأمبر الحديث، والكتاب منشور على على موقع مركز الدراسات 
نشأة وتطور منظات الجنتع المدني في المجتع الإسلاي مقارنة بالغرب - د. وائل علي المهدي أبو كووق

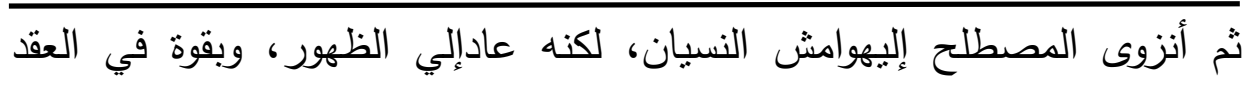
الأخير من القرن العشرين. ويعزو المحللون هذه العودةالقوية وهذا الإحياء المصاحب لمصطلح المجتمع المدني إلي إنهيار الكتلة الثرقية كما سبق ذكر لـن ذلك.

حيث جاء مفهوم المجتمع المدني ليعبر عن هذه الحال أو العملية التاريخية

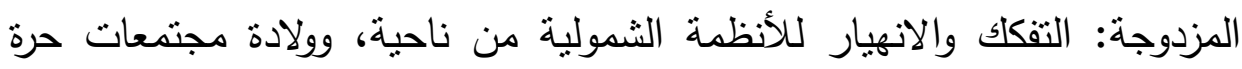

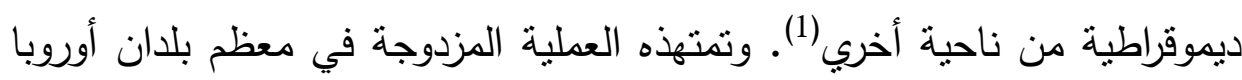

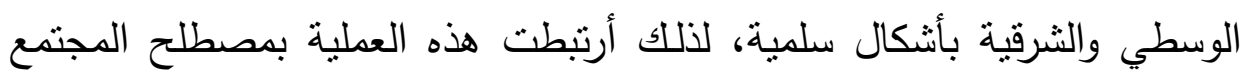

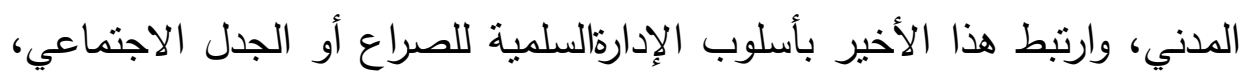

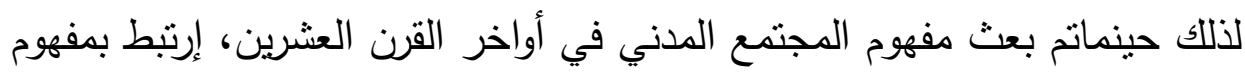

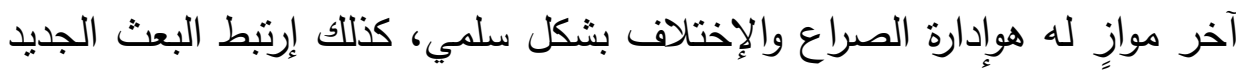

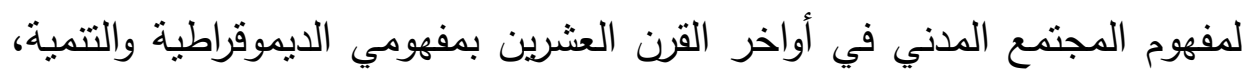

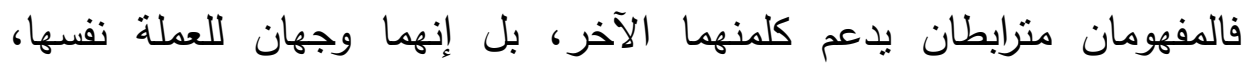

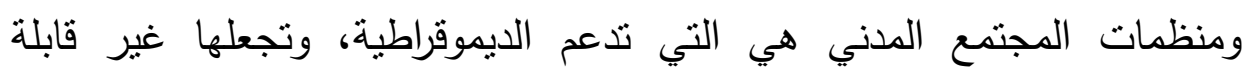
للانكفاء أو الارتداد، كذلك تزامن بعث مفهوم المجتمع المدني فيالتسعينات

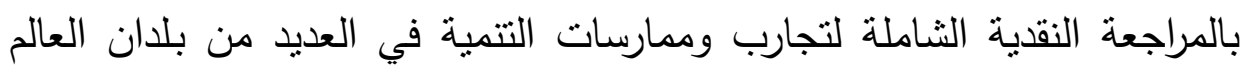
الثنالث (2).

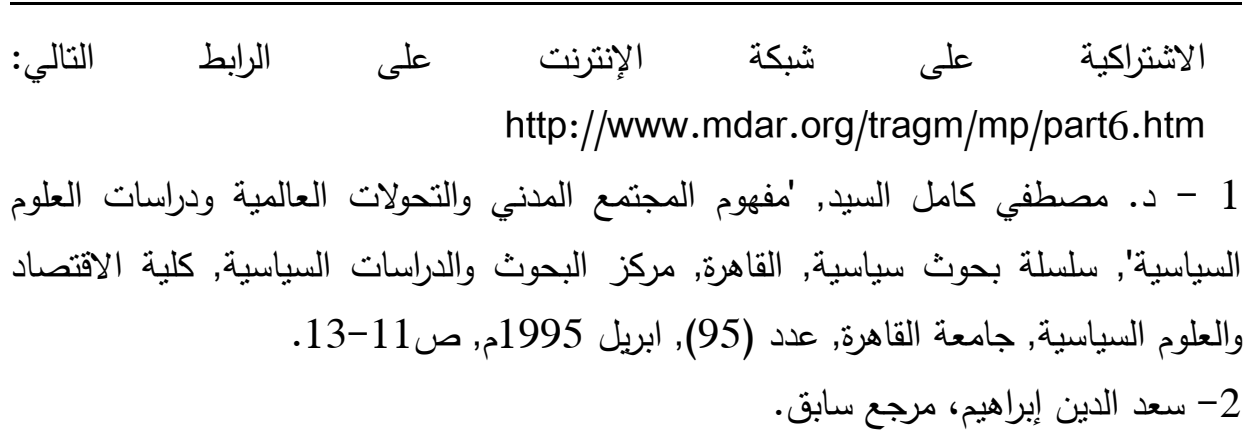




\section{المبحث الثاني}

\section{نثأة منظمات المجتمع المدني في الغرب}

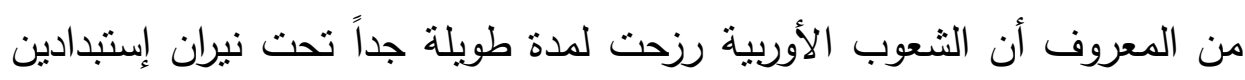

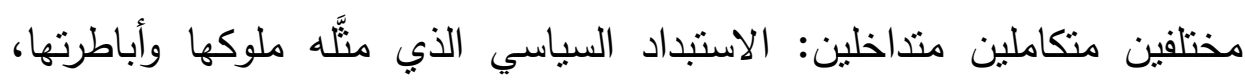

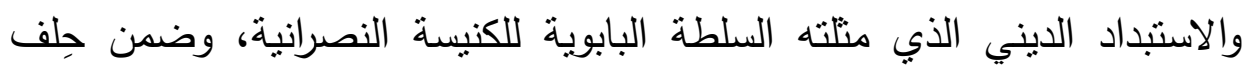

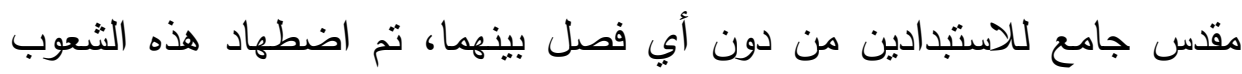

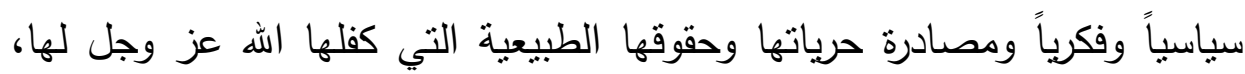

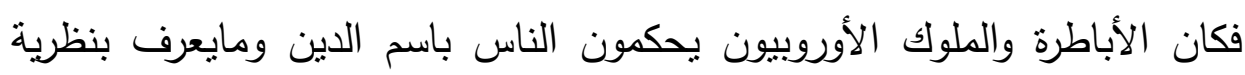

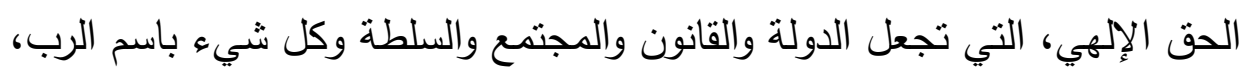

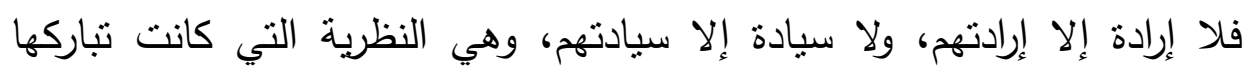
السلطة الكنسية وتعضدها، ضمن ذلك الحلف المقس الذادي يضمن إلادي تبادل

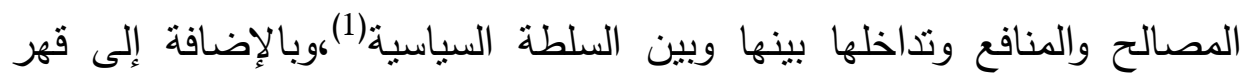
الثعوب ومصادرة حرياتها وحقوقها؛ فقد نثِبت كثثر من الحروب الدئه الدينية الأوروبية المشهورة، وتفشت ثقافة التعصب واللاتسامح في المجتمعات الأوروبية. ومع تطور

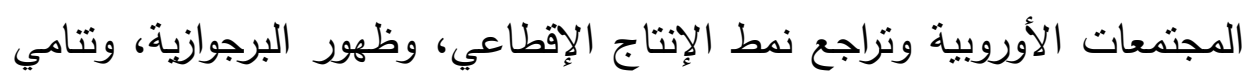

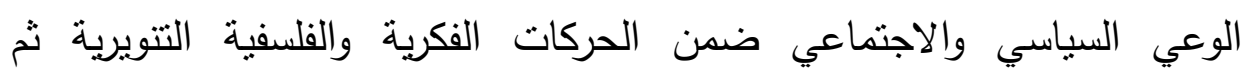
الحداثية، تعالت أصوات مفكري أوروبا ورواد نهضتها ضد أولائل الاستبداديون (2).

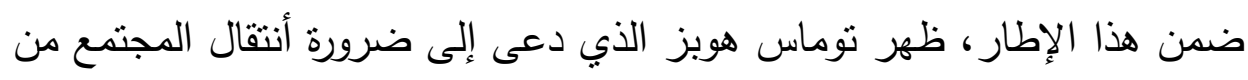

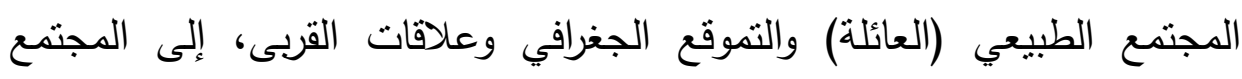
1 - ناهد عز الدين، 'الدجتمع الدني'، موسوعة الثباب السياسية، عدد (5)، القاهرة: مركز

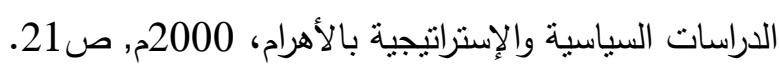

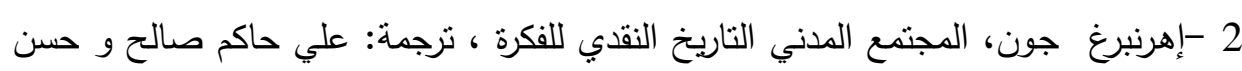

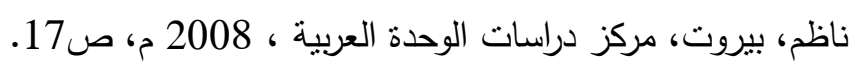




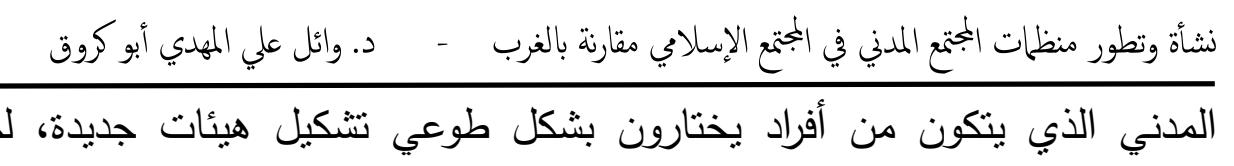

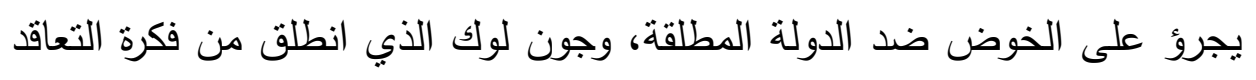

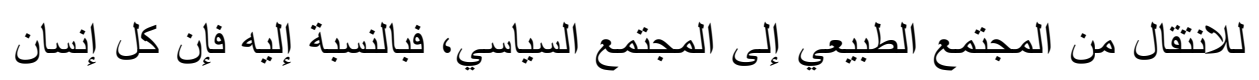

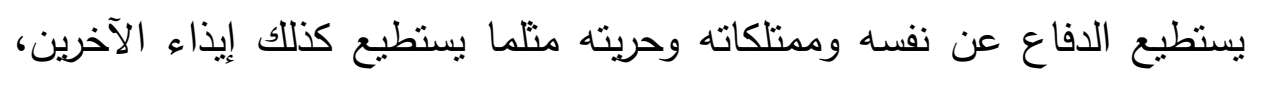

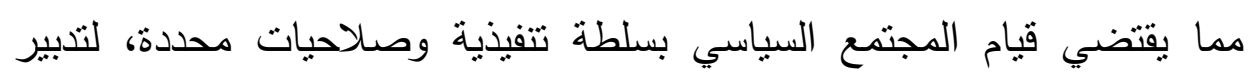

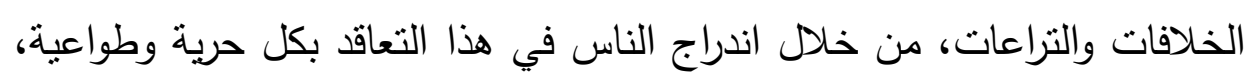

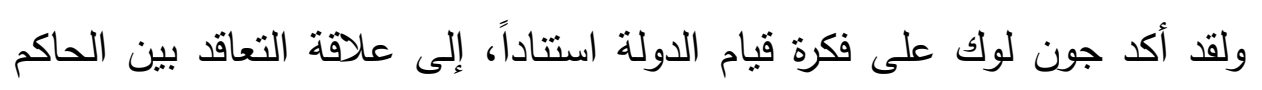

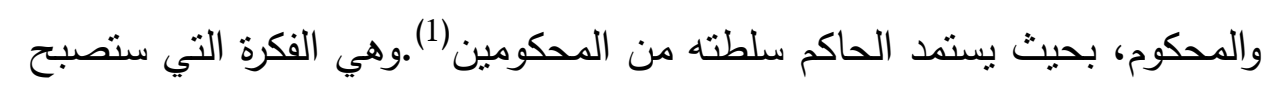

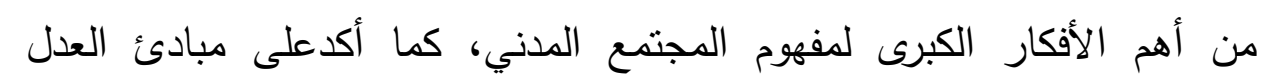

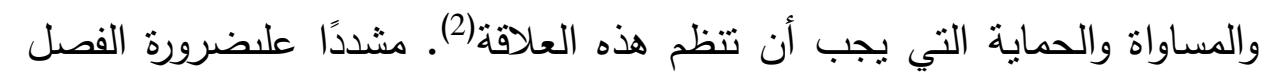

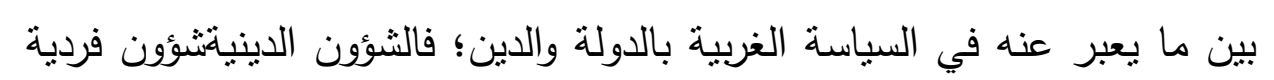

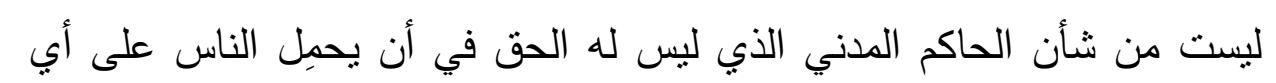
معتقد، لأنه غير مفوض من الرب، بل من رعاياه(3). بذلك وضع جون لوك اللبنة الأساس للتمييز بين السلطة المدنية والدينية، وللقضاء

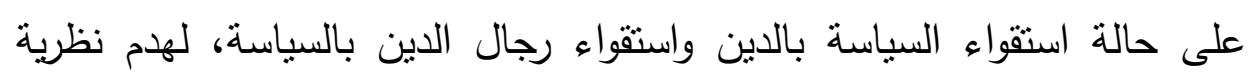
التفويض الإلهي للحاكم، ليفسح المجال لتنامي الحيز المدني في حياة الناس رلأ ومجتمعاتهم على أساس نظرية التعاقد. هذه النظرية ازدادت وضوحاً على يد جان جاك الثيان روسو الذي طورها في كتابه

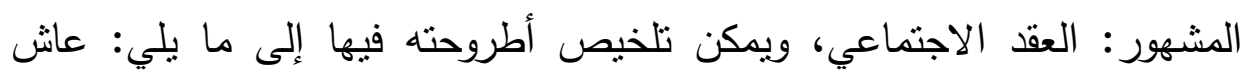
1- جون لوك، رسالة في التسامح، ترجمة: منى أبو سنة ، تقديم : مراد وهبة، المجلس الأعلى

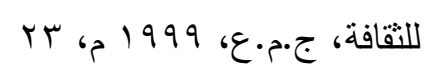

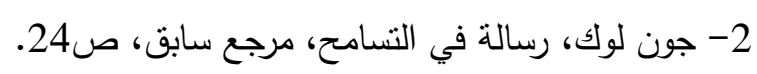

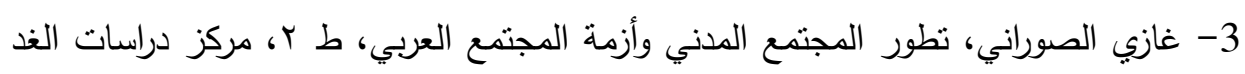

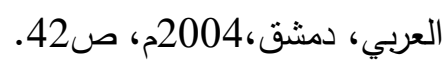


الناس قبل ظهور الدولة على حريتهم الكاملة، لكن نظراً لتعارض المصالح

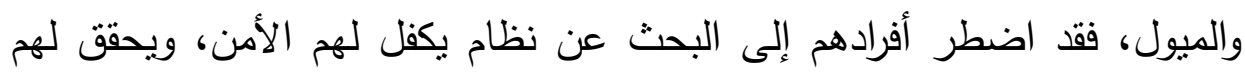

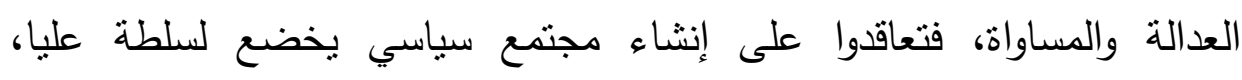
مفتحين بذلك أساس نثأة الدولة وسند السلطة معاً، فتتازلوا عن حرياتهم الطبيعية

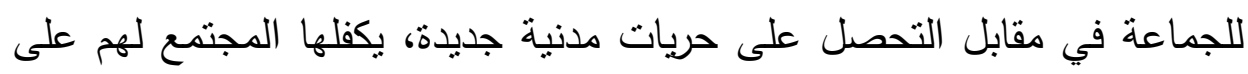

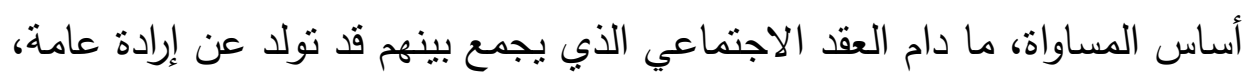

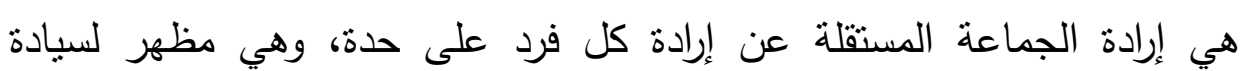

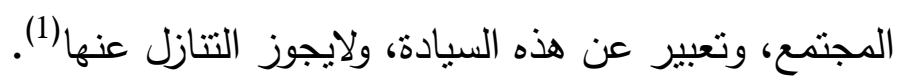

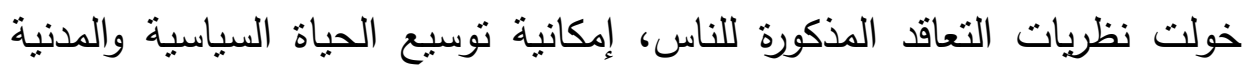
بينأفرادهم وجماعاتهم لضمان العيش المشترك بينهم على أسس عادلة وسليمة، وأسهمت هذه النظريات بصفة أساس وحاسمة؛ في انطلاق سيل غزير لفئ من الأفكار السياسية والاجتماعية التي أنتجها المفكرون المذكورون وغيرهم؛ لتقوية الصفة وهية فئنة

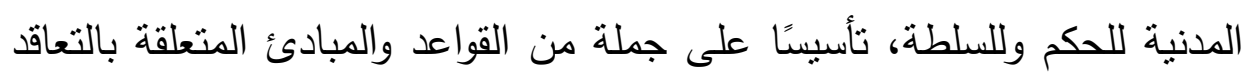

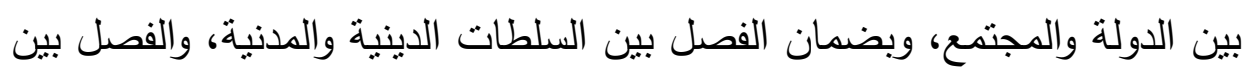

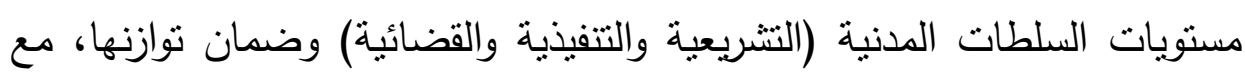
التأكيد على سيادة الثعب، وتمثيل نفسه عبر وسيلة الاقتراع العام وغيرها من ونئن المبادئ التي تتتاسل من بعضها، لتفضي إلى تثكيل مبادئ حقوق الإنسان

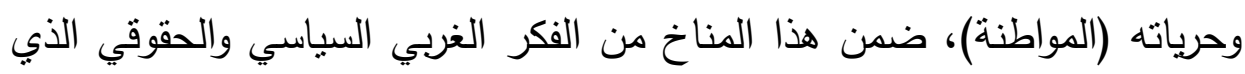

1- جان جاك روسو، العقد الاجتماعي أو مبادئ الحقوق الأساسية، نقله إلى العربية: عادل

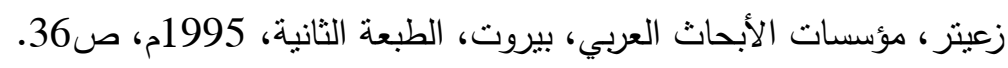


نشأة وتطور منظات الجمتع المدني في الجنمع الإسلاي مقارنة بالغرب - د. وائل علي المهدي أبو كروق

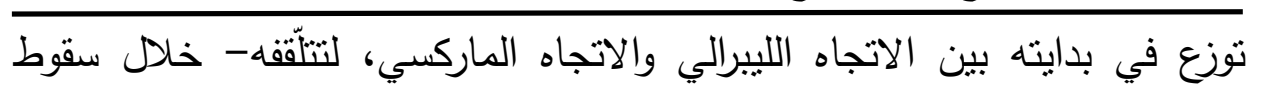
الأنظمة الثمولية في أوروبا الثرقية وبعيده(1). الاتجاهات الفكرية الراهنة في العالم المعروفة بفلسفات ما بعد الحداثة، إذ ندت فكرة

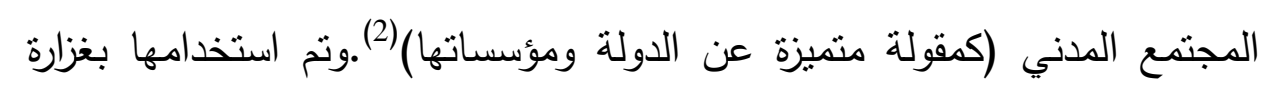

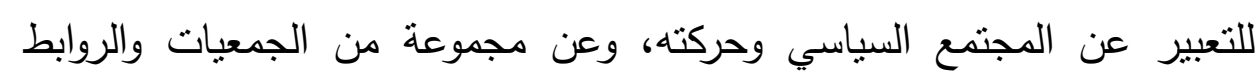

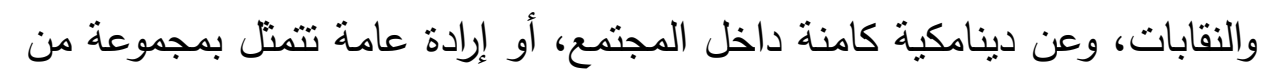
الإرادات الفردية الباحثة عن الخيرالعام (3).

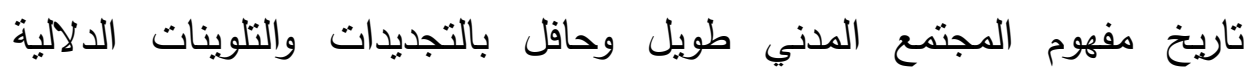

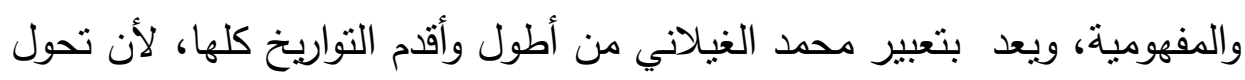

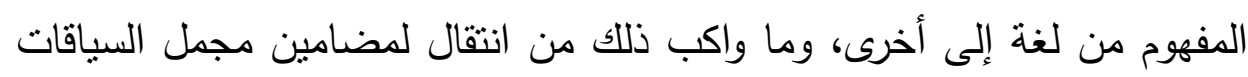

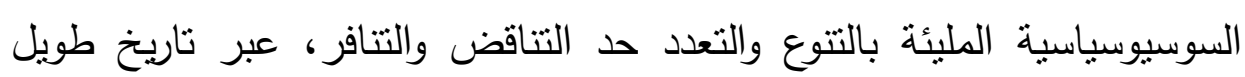
ومعقد، يضعنا أمام مفهوم تاريخي شديد الحساسية إزاء التعريفات الإجرائية(4).

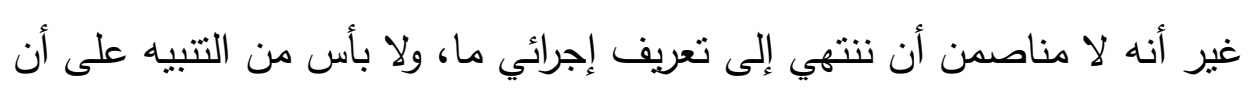

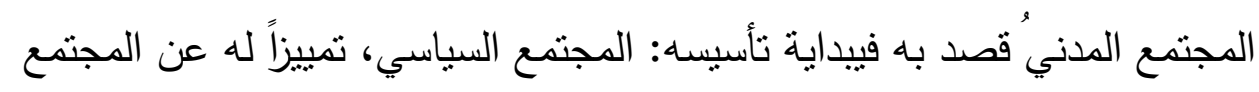

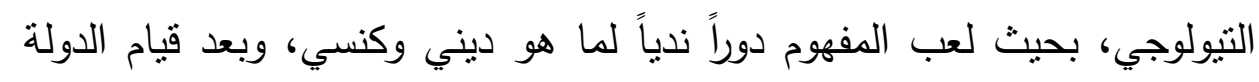
على أساس هذا التعاقد، أضحى الدفهوم يستخدم لمواجهة الدولة وسلطانها وللثقليل

1 - عمربرنوصي، مفهوم المجتمع المدني بين الفلسفة السياسية الغربية والسوسيولوجيا المعاصرة

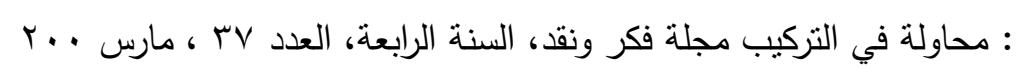

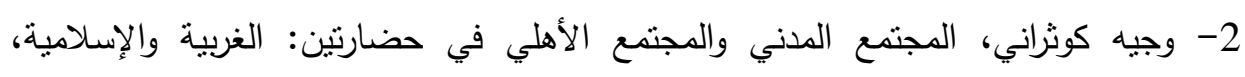

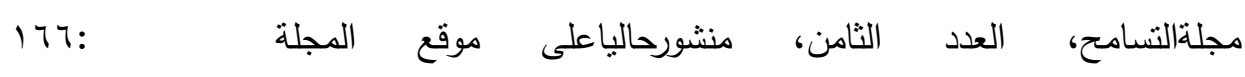
:http://www.altasamoh.net/Article.asp?ld

$$
\text { 3- - نس المرجع. }
$$

4- محمد الغيلاني، محنة المجتمع الدنني: مفارقات الوظيفة ورهانات الاستقلالية، دفاتر وجهة

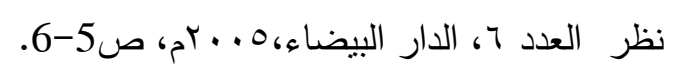


من سلطانها وهيمنتها، من أجل توسيع الديمقراطية والحريات والحقوق والعدالة والمساواة، ولضمان التتمية المستدامة والسلام العادل والتجارة العادلة وحماية البيئة

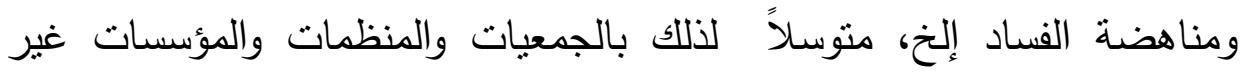

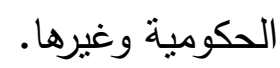

ويمكن أن نختزل تعريفات المجتمع المدني إجرائياً كما نقول كثير من الدراسات

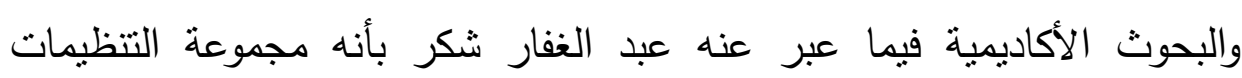

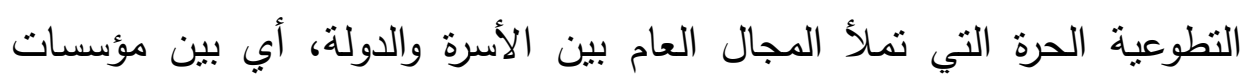

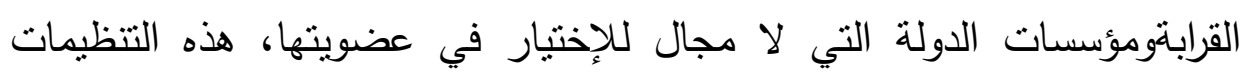

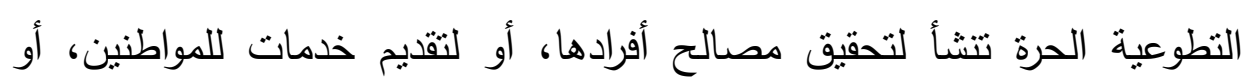
ممارسة أنشطة إنسانية متتوعة، وتلنزم في وجودها ونشاطها بقيم ومعايير الإحترام والتراضي والتسامح، والمشاركة والإدارة السلمية للتنوع والإختلاف (1).

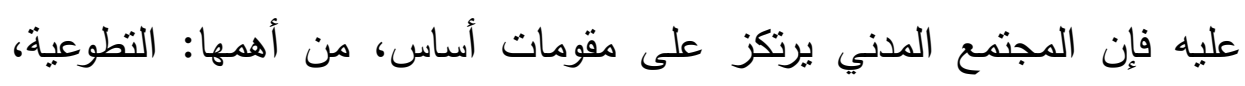

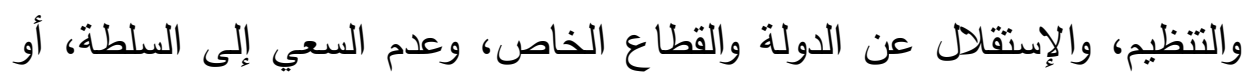

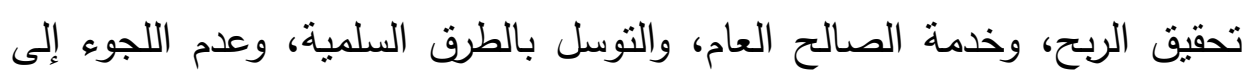
العنف.

تجمع الدراسات والبحوث على أن المجتمع المدني أضحى اليوم من المكونات

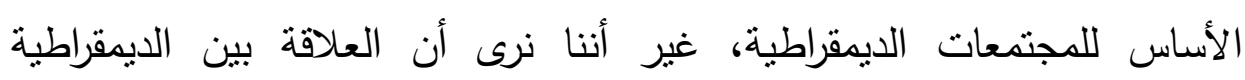

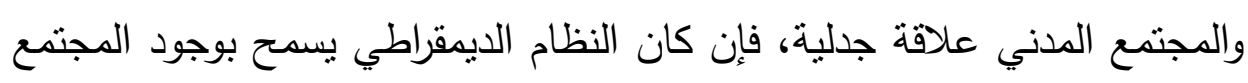

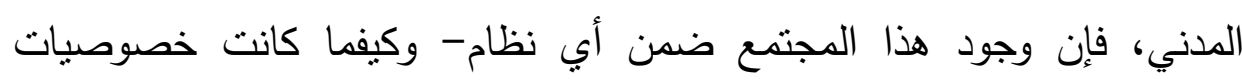

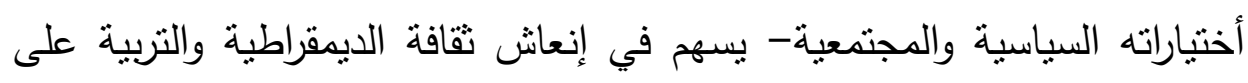

1- عبد الغفار شكر، المجتمع الأهلي ودوره في بناء الديمراطية، سلسلة حوارات لقرن جديد،

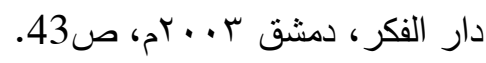




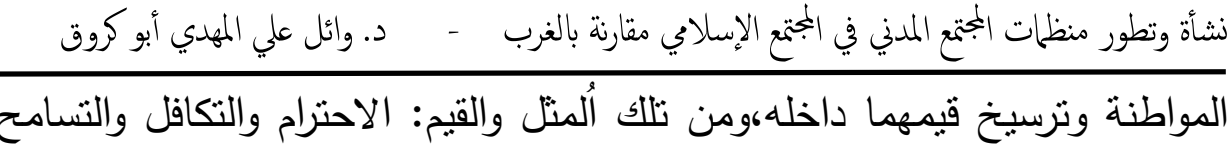
والحرية والمسؤولية والتعامل المؤسسي، كما يساعد كذللك على توسيع قاعدة الاهتمام بالمصلحة العامة وتعزيز مشاعر الاتتماءات الوطنية والإقليمية، وتقليص

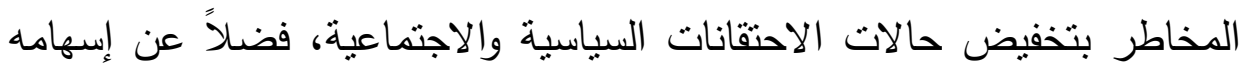
في إعداد النخب وفرز القيادات الجديدة(1). إذا كانت تلك هي أصول المجتمع المدني في الفكر الغربي وماهيته ومقوماته وقيمه ورهاناته التي لم تخرج عن أسئلة الدين والدولة والحريات والحقوق، فإلى أي ألى الدي

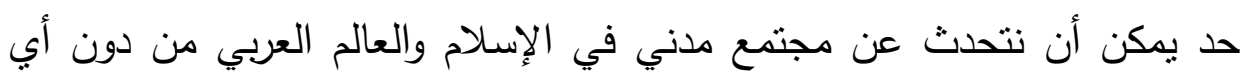
تجن على خصوصيات الإنسام العقدية والنتريعية والتاريخية. المبحث الثالث

\section{نثأة وتطور منظمات المجتمع المدني في الاسلام}

شكلت نشأة وتطور منظمات المجتمع المدني في الاسلام والعالم العربي هاجساً

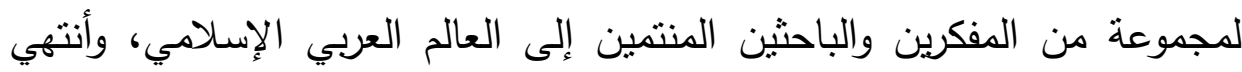

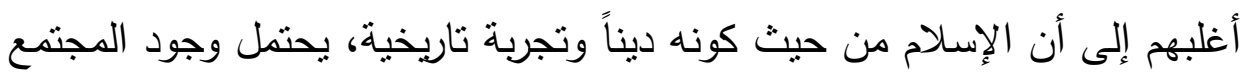

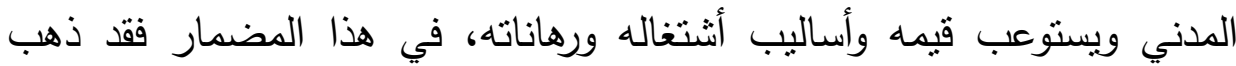

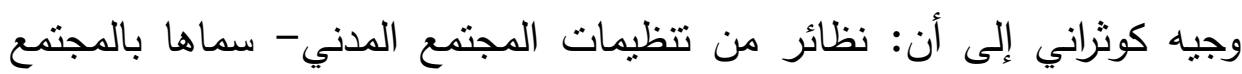

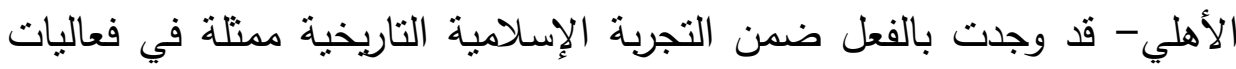

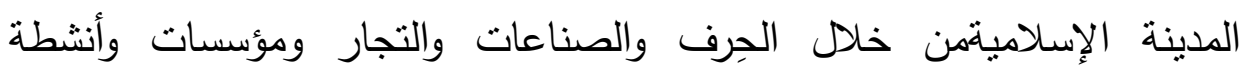
الأوقاف، التي حاولت أنتضمن إستقلالها المدني عن الدولة الممثلة في مؤسسات

1- متروك الفالح، المجتمع والديمقراطية والدولة في البلدان العربية، مركز دراسات الوحدة

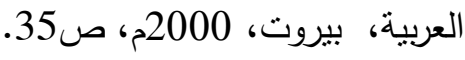


الوالي، والقاضي، وصاحب الثرطة(1). وإلى ذلك نفسه ذهب صبري محد خليل،

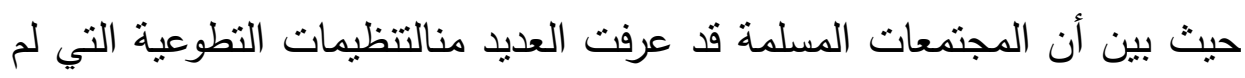
تستهدف الربح، والتي تمتعت بقدر منالإستقلال عن الدولة(2).ممثلاً عليها

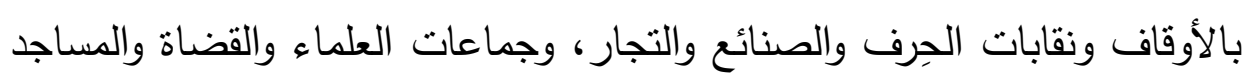

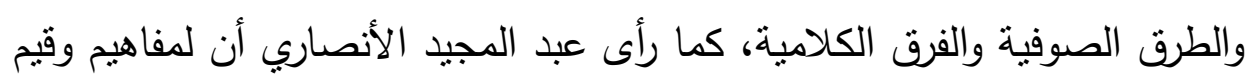

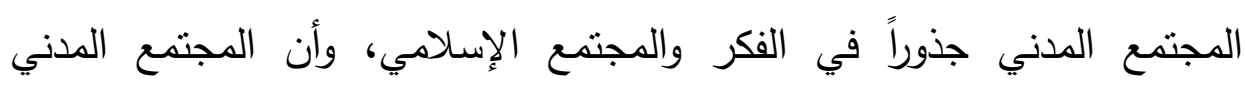

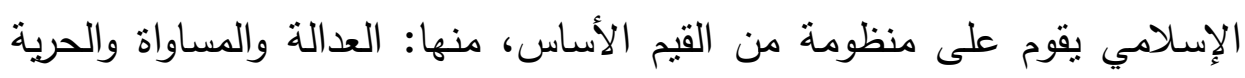
والتشاور وحق الإختلاف والتسامح والتعاون والتكافل (3).

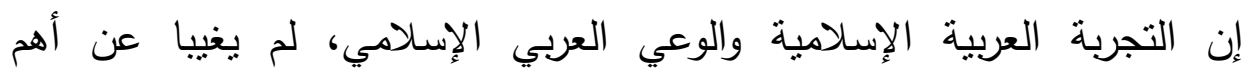

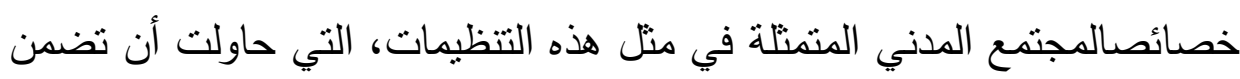

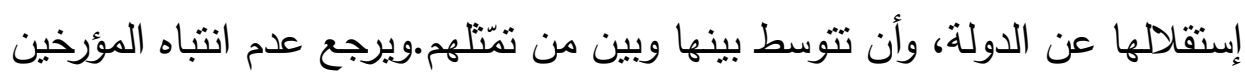

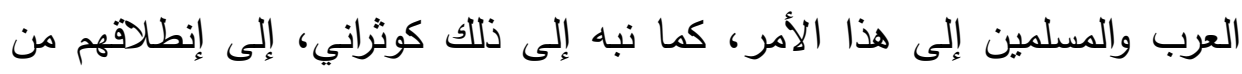

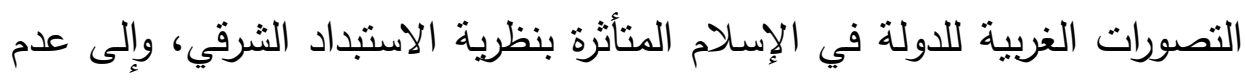

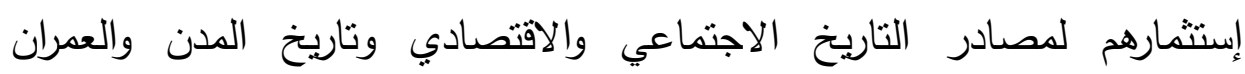
والسكان(4). ويكفي الرجوع إلى مثل هذه المصادر والدراسات القليلة، بما فيذلك والكاني

1- وجيه كوثراني،المجتمع الدني والمجتمع الأهلي في حضارتين: الغربية والإسلامية، مرجع سابق،

2- محمد خليل صبري، مفهوم المجتمع الدنني بين الفلسفة السياسية الغربية والفكر السياسي الإسلامي - المي 3- عبد المجيد الأنصاري، جذور ومظاهر المجتمع المدني في الفكر والمجتمع الإسلامي، علي الرابط: http://www.iraqcenter.net 4- وجيه كوثراني، المجتمع المني والمجتمع الأهلي في حضارتين: الغربية والإسلامية، مرجع سابق، 
نشآة وتطور منظات الججتع المدني في المجتع الإسلاي مقارنة بالغرب - د. وائل علي المهدي أبو كروق الغربية منها التي استثرتها، للوقوف على هذا الأمر والاستخ لال عليه، مما يعفينا من الإطالة فيه(1).

على الرغم من كون الإسلام قد عرف هذه التنظيمات الثبيهة بتنظيمات المجتمعالمدني، فإن ذلك لا يكفي وحده للتنليل على حديثنا، ولا غرو في ذلك ما لإنا دام أنه لا يصح أختزال المجتمع الددني في هذه التنظيمات المستقلة أو شِبه فيه

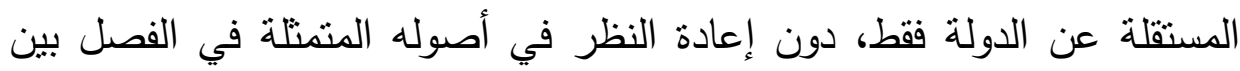
الدين والدولة، وما نتج عنه خلال تاريخه الطويل، من ترسيخ لحقوق الإنسان

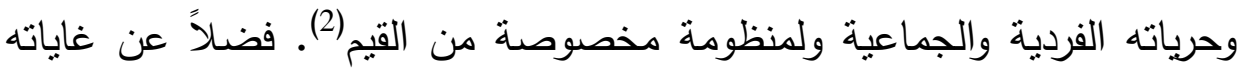

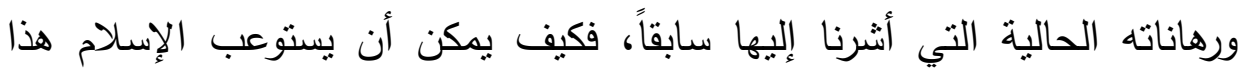

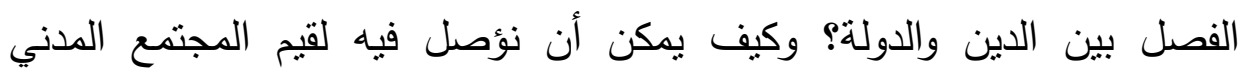
ولمختلف هذه الحقوق والحريات والرهانات التي لا يمكن أن نتحدث عنه من لن لناني

دونها?

1- يمكن الرجوع إلى المصادر والدراسات التي أثتنها وجيه كوثراني في دراسته، ودراسة رضوان

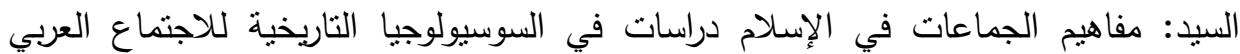

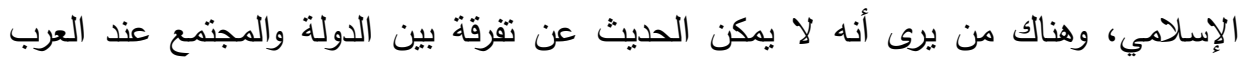

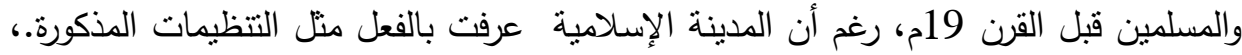

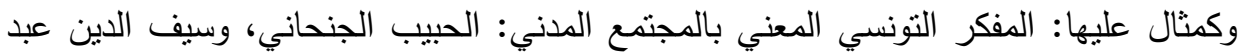

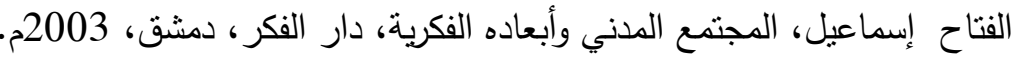

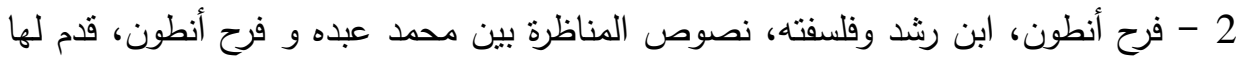

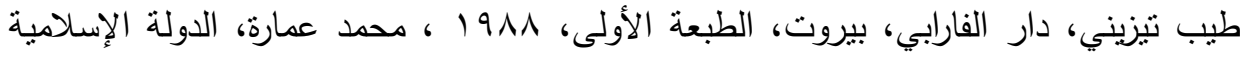

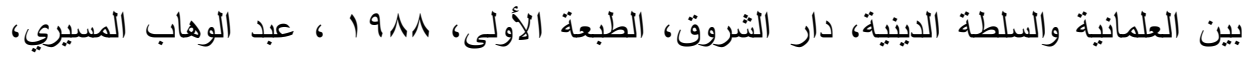

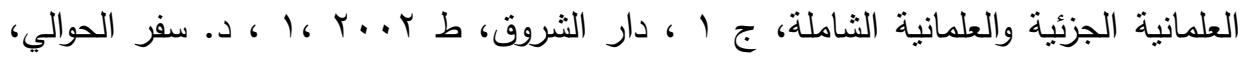

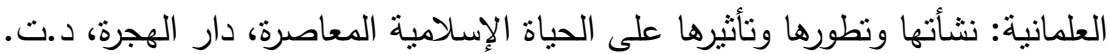




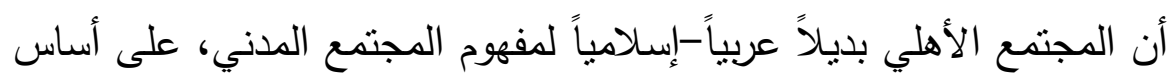

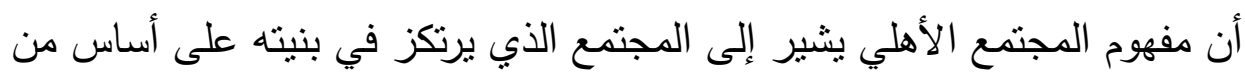

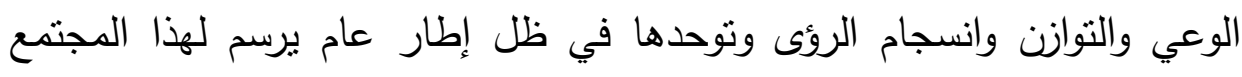

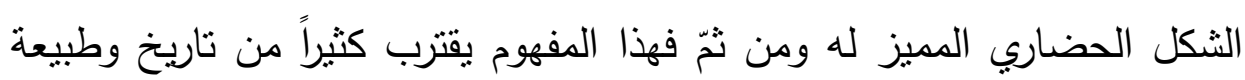

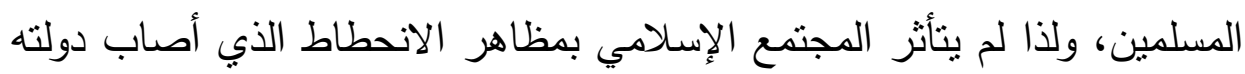

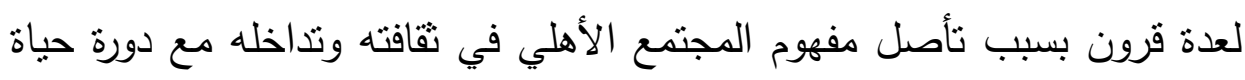

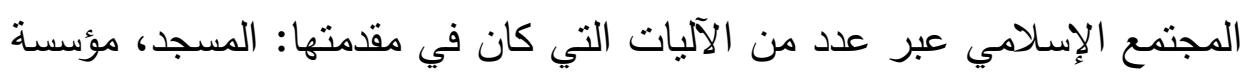

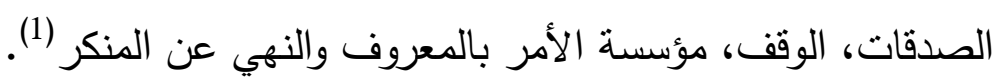

\section{الدين والدولة في الإسلام بالنظر إلى مقتضيات المجتمع المدني}

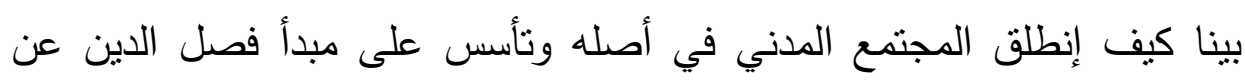
الدولة فيالغرب (العلمانية)، لذا رأى بعض المئيع المسلمين أن لا محل للمجتمع المدني

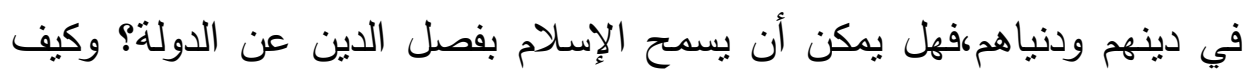

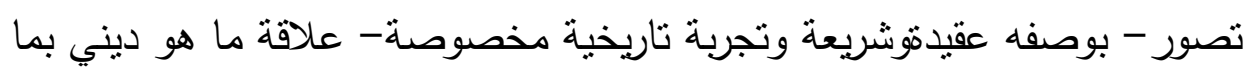
هو مدني بين أهله وفي مجتمعاته؟ بونه

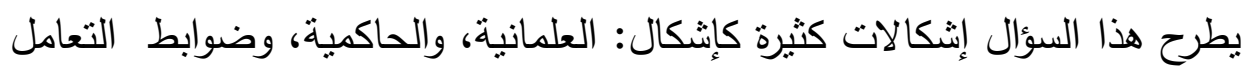
بين الحاكم والمحكوم في الإسلام وغيرها.

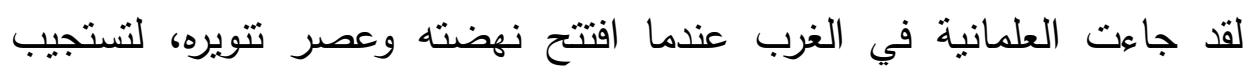

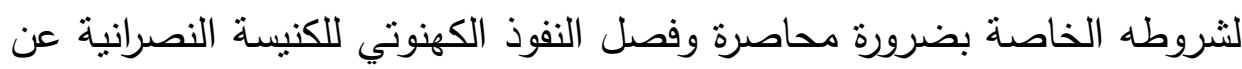

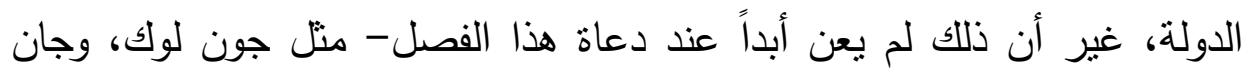
1 - عبد الله موسى، المجتمع الأهلي: المشروع المغيب ودور السلطة، مجلة النبأ، العددين

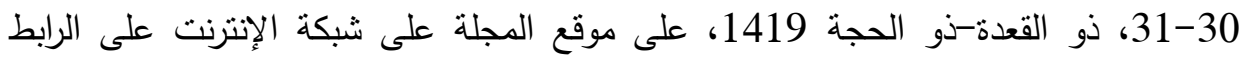

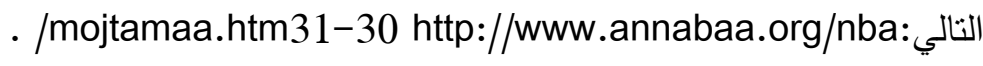




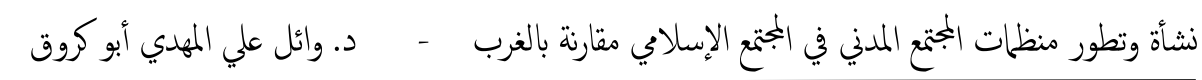

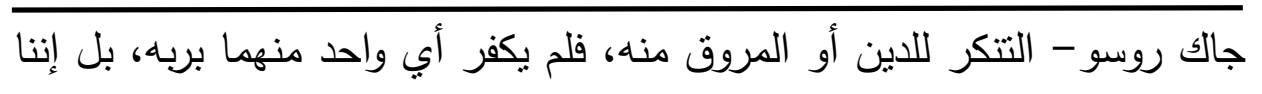

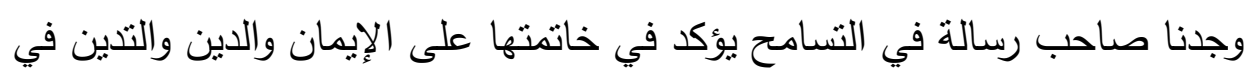
التعاقد الذي يعنيه(1). لعل سمعة هذا المفهوم السيئة التي إكتسبها في العالم العربي والإسلامي التي

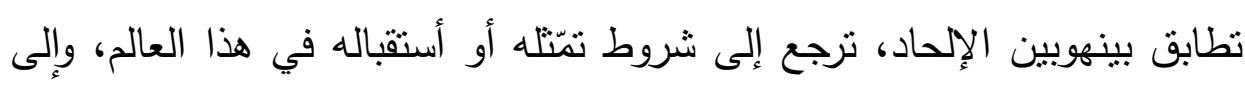

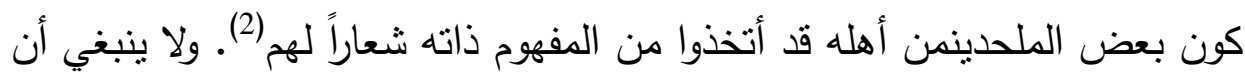

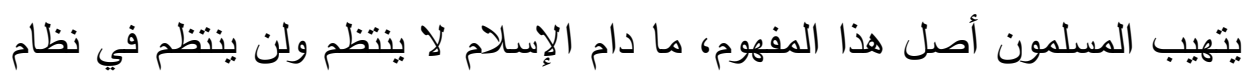

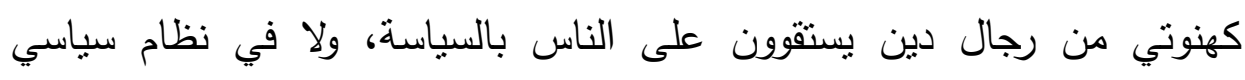

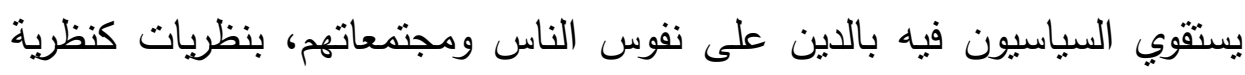
التفويض الإلهي المطلق للحاكم(3). فإذا كان الأمر في الإسلام على هذا الثكل، نكون على شكل متميز عنها

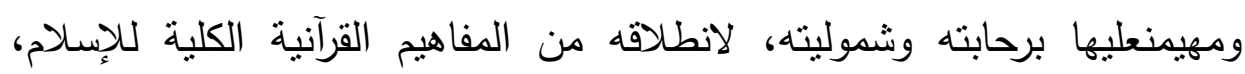

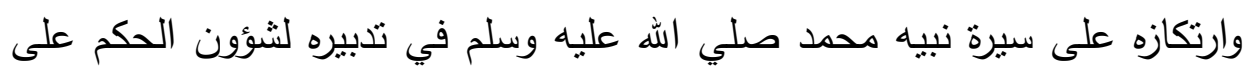

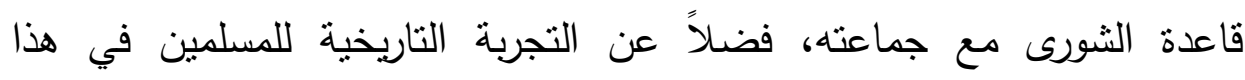

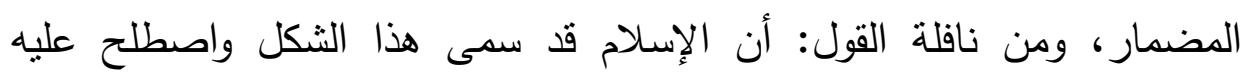
بمصطلح: البيعة، الذي يشكل مفهوماًدينياً قرآنياً أسعف المسلمين فيتأسيس الدول الدال

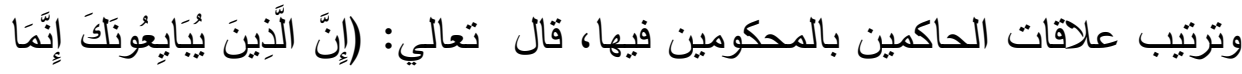

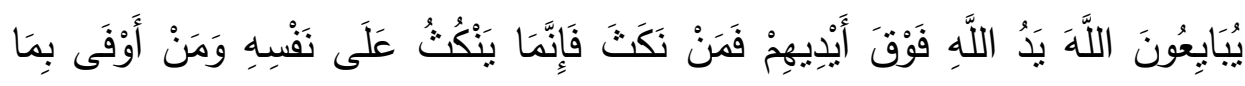
1- الإمام محمد عبده، الأعمال الكاملة، تحقيق وتقديم: محمد عمارة، دار الثروق، القاهرة،

$$
1993 \text { ، ج ج. } 107
$$

2- عبد الوهاب المسيري، العلمانية الجزئية والعلمانية الثاملة، ج 1، دار الثروق، ط 2002م، ص103.

3- ميثاق العلاقة بين الحاكم والمحكومهمؤتمر العالم الإسلامي المشكلات والحلول، رابطة العالم

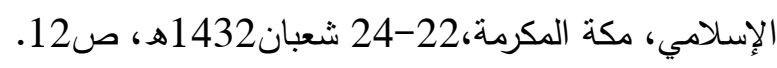




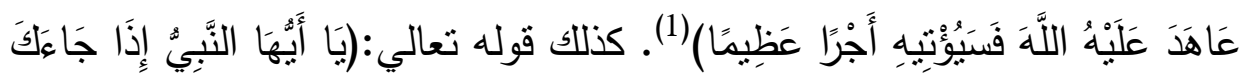

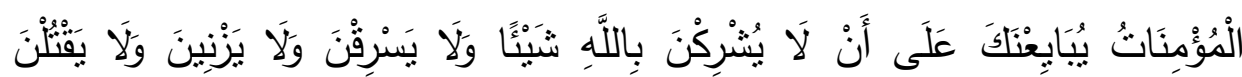

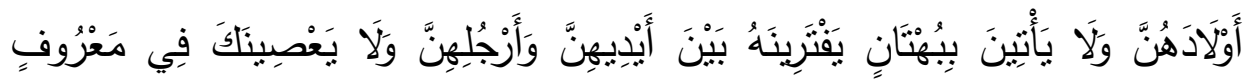

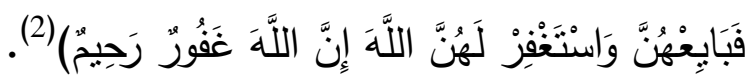
معلوم أن كثيراً من العلمانيين الملحدين قد أنكروا على الإسلام - كما بين

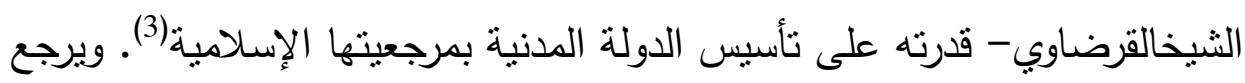

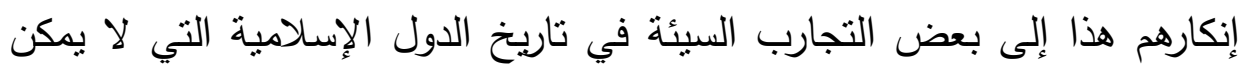

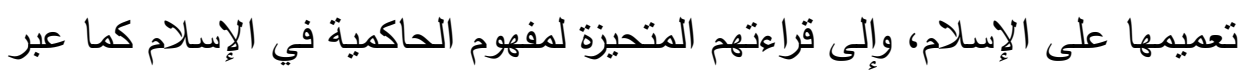

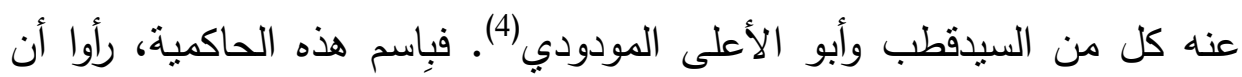

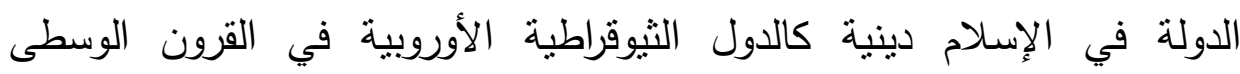

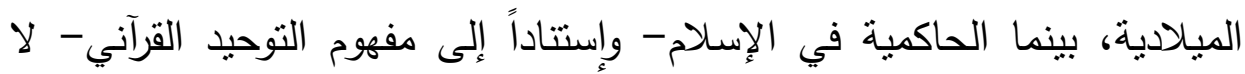
تعني أكثر من أنه يتعين على المسلمين الموحدين إسناد السلطة المطلقة في

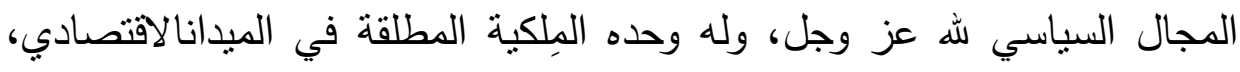

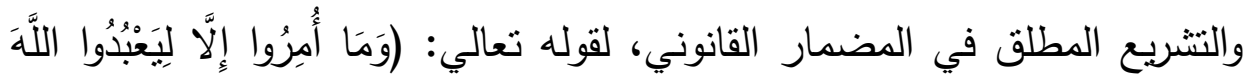

$$
\text { 2- سورة الفتح، الآية10 سورة المتحنة، }
$$

3- أحمد فؤاد عبد الجواد عبد المجيد، البيعة عند مفكري أهل السنة والعقد الاجتماعي في الفكر الإسلامي الحديث، دراسة مقارنة في الفلسفة السياسية، دار قباء، القاهرة، 199 4- سيد قطب، معالم في الطريق، عرض وروئة فتحي الثقاقي، دار الثرروق، القاهرة، 1992.

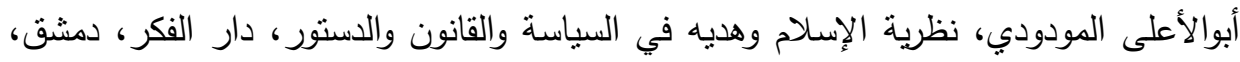

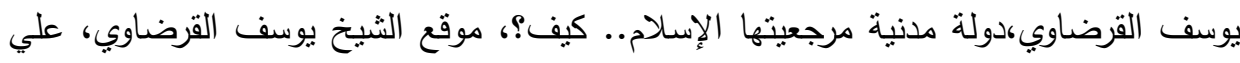
http://www.qaradawi.net:الرابط 


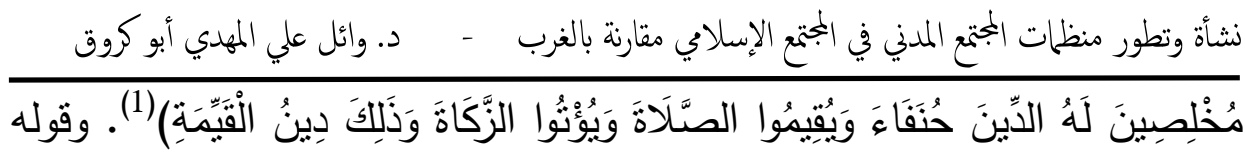

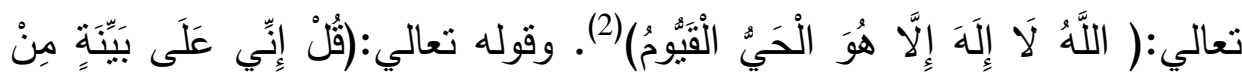

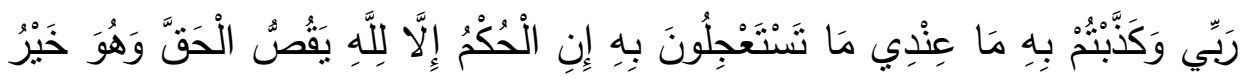

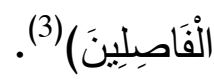
مما لا شك فيه أن مفهوم التوحيد القرآني يعني- كما يقول صبري محمد خليل-

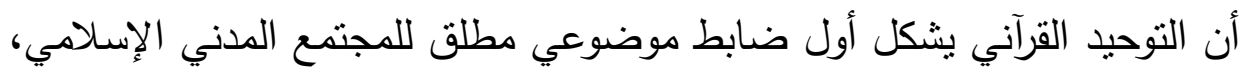

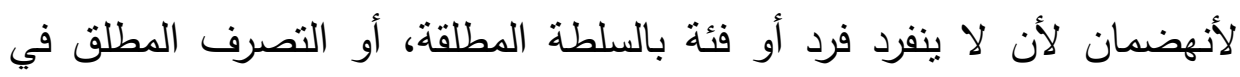

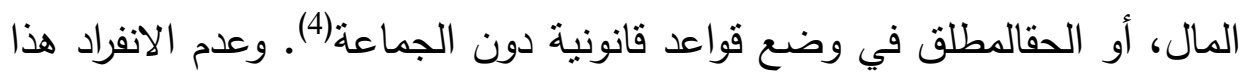

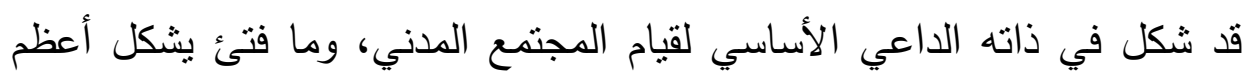

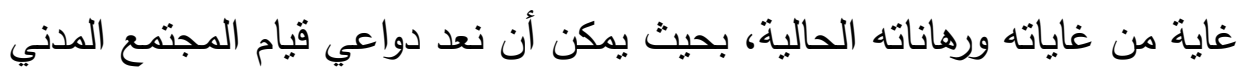

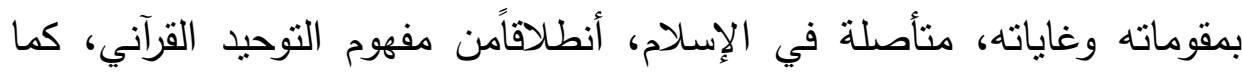

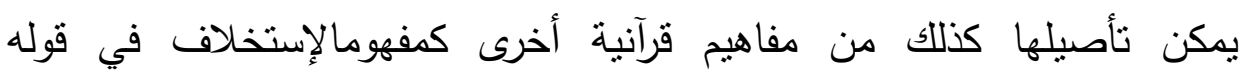

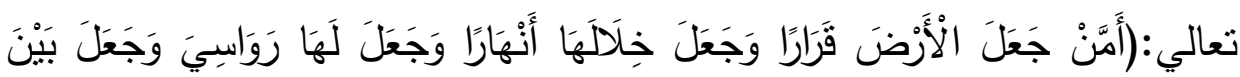

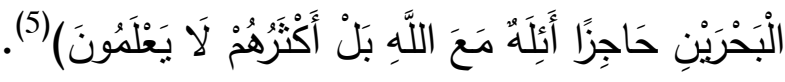
فقد أستخلف اله عز وجل الناس في الأرض مقابل نوحيده، وأسند إليهمأمرهم

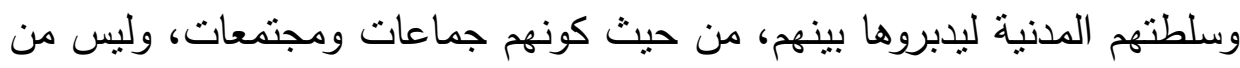

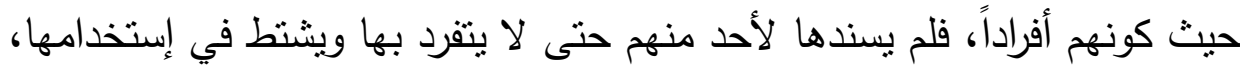

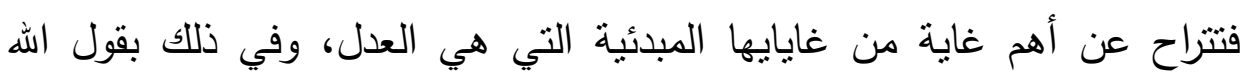

1-سورة البينه، الآية5.

2- سورة آل عمران الآية2.

3- سورة الانعام، الآية

4 - محمد خليل صبري، مفهوم المجتمع الددني بين الفلسفة السياسية الغربية والفكر السياسي، الإسلامي، مرجع سابق، ص36. 5- سورة النمل، الآية 62. 


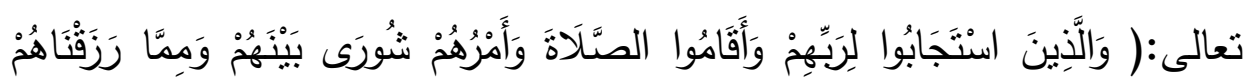

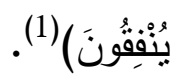

فلا أحد في الإسلام يمكنه أن يدعي التقويض الإلهي أو الحق الإلهي في السلطة

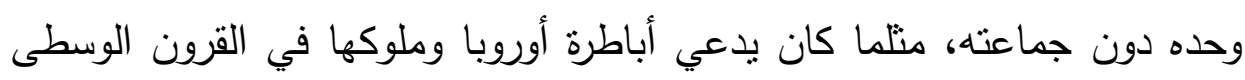

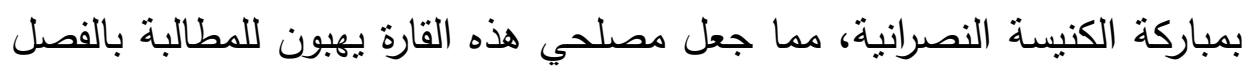
بين الدين والدولة(2). الأمر أو السلطة في الإسلام- بمقتضى نصوصه القطعية الدلالة والثبوت- يرجع إلى جماعة المسلمين ومجتمعهم، لا إلى فرد من أفرادهم، بين ذلك كثئ الإنير من فقهاء

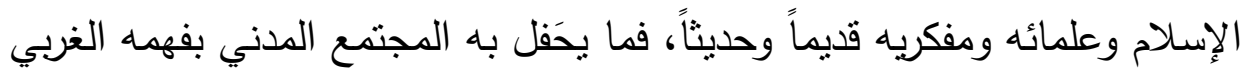

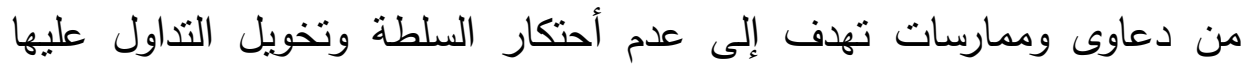

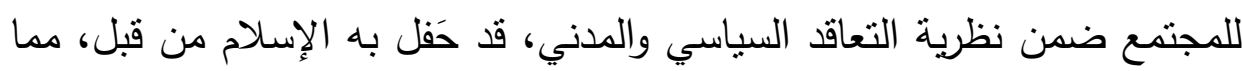

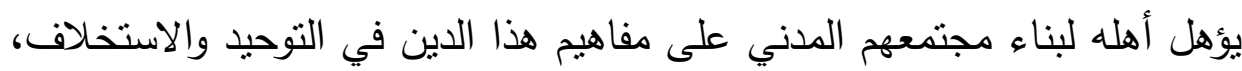

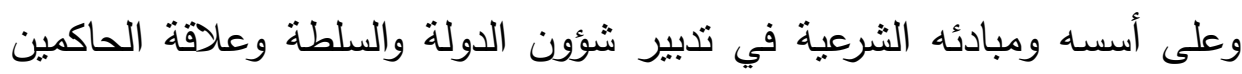

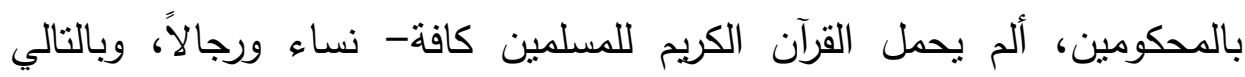

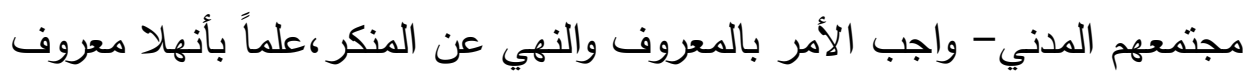

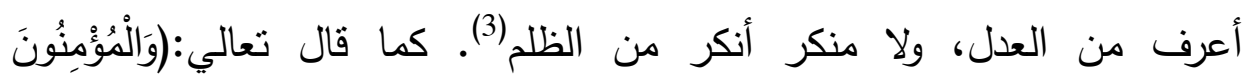

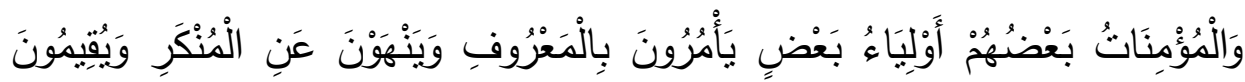

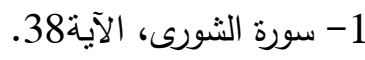

$$
\begin{aligned}
& \text { 2- 2 - عبد المجيد الانصاري، مرجع سابق الابن } \\
& \text { 3-أحمد صبحي منصور ، الاسلام والمجنمع المدني و سلطة الحاكم، علي الرابط: }
\end{aligned}
$$
.htm I TVr $\varepsilon$ http://forum. sonsofegypt.net/t 


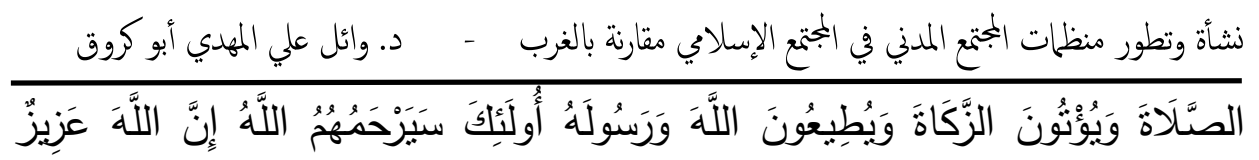
حَكِيمُ2) لقد تضمن الإسلام أسس نظرية التعاقد السياسي والإجتماعي، وبالتالي الأسس

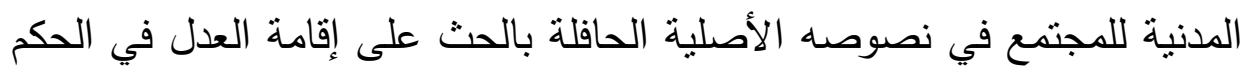

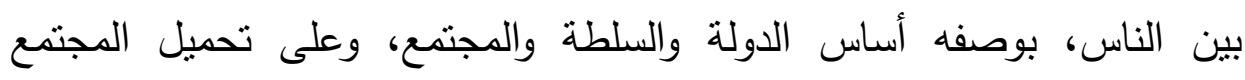

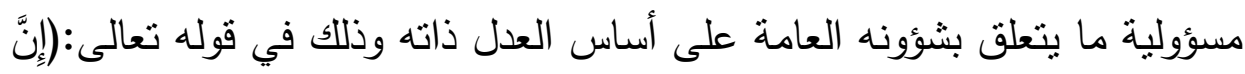

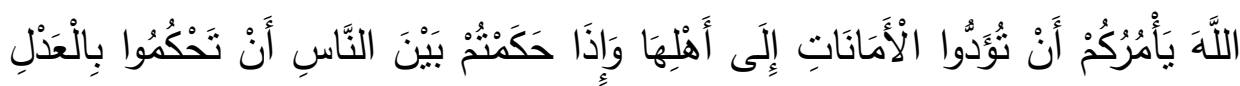

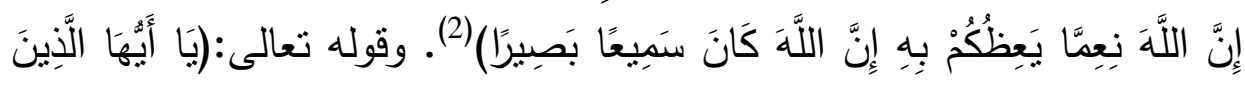

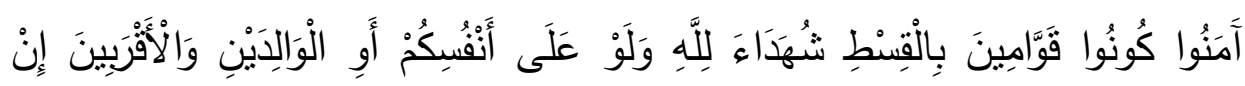

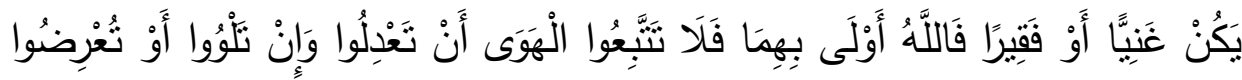

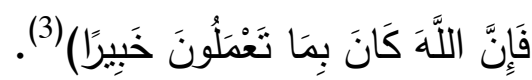
كما تضمن الإسلام نفس الأسس في تجربته التاريخية، وإن لم يعبر عنها بهذا لفئا

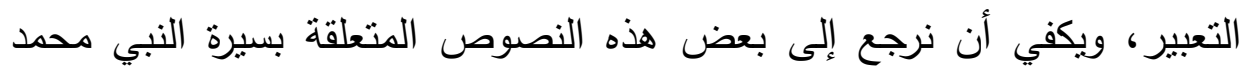

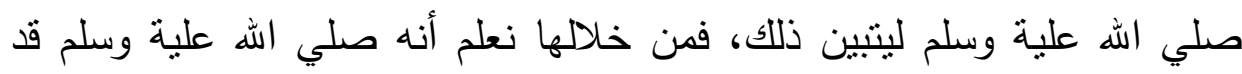

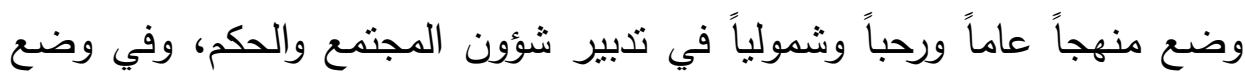
قواعد البيعة أو التعاقد السياسي والمدني بين الحاكم والمحكوم(4).

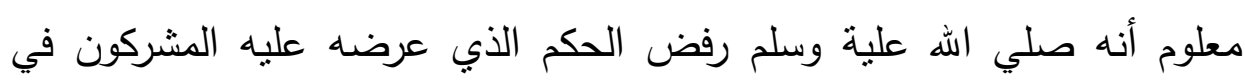

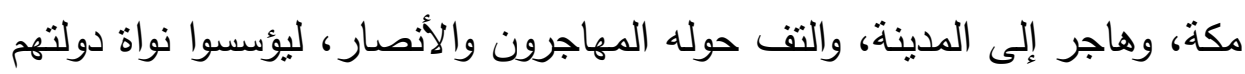

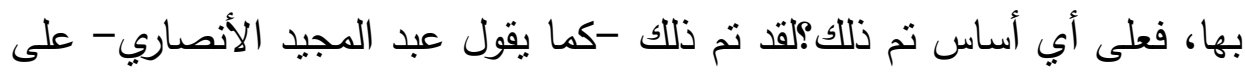

$$
\text { 3- } 2 \text { - سورة التوبة، الآية } 72 .
$$

4

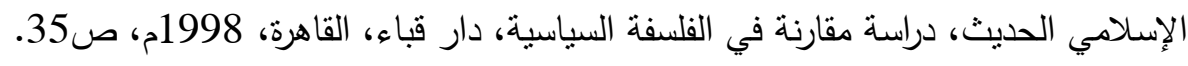


حقيقه وبارادة طوعية حرة (بيعة العقبة الثانية)، ودستور نظم حقوقاً وواجبات بين جماعات حرة متعددة الديانات والأعراق، وفي إطارٍ من قيم العدالة والتكاقل والتشامح والتشاور والحرية(1). لقد استمد الرسول صلي الله علية وسلم سلطته في تكوين الدولة الإسلامية الأولى والمجتمع الإسلامي الأول، ممن التفوا حوله عن طواعية، في الوقت الذي كانوا فيه قادرين على أن يتركوه لمصير آخر، إذ علم كيف يستشيرهم في الأمر، وهو الإنيا

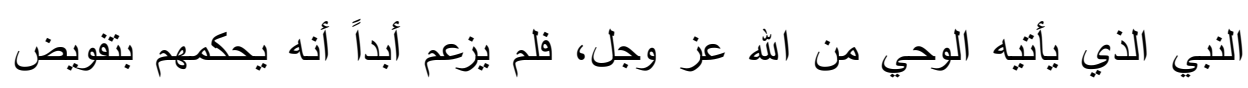
إلهي، بل نزل الوحي الإلهي ليؤكد على النبي صلي الله علية وسلم ويأمره بأن يكون سهلا ليناً كي لا ينفض عنه أصحابه فيضيع سلطانه، ويأمره بأن يعفو عنهم

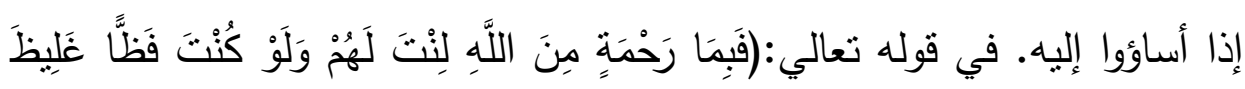

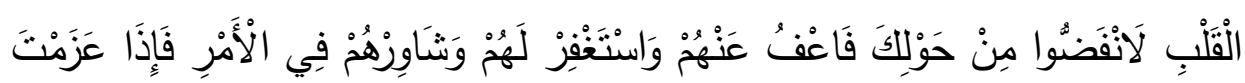

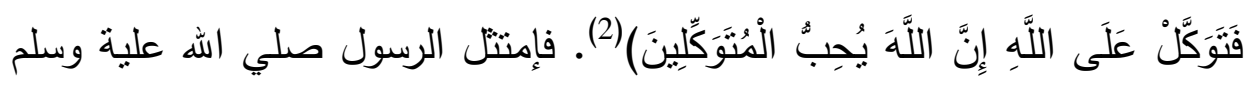
لأمر الله عز وجل فجعل من مبدأ الشورى منطلَقاً لاستمداد سلطته الدنيوية والمدنية، فلقد أستشار المسلمينفي قتال قريش يوم بدر، فقال له الأنصارلا نقول كما

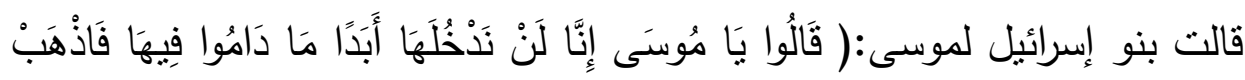

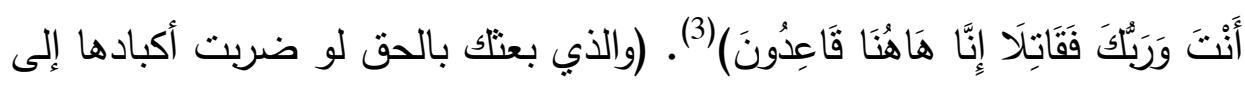

1 - عبد المجيد الأنصاري، جذور ومظاهر المجتمع المدني في الفكر الإسلامي، أصول

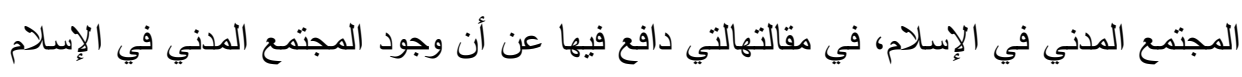
سابق عن تكونه دولته ، ومهيمن عليها بعد يتكوينها، مرجع سابق. 2- سورة آل عمران الآية 159. 3- سورة المائدة الآية 24. 
نشأة وتطور منظات الجمتع المدني في الجنتع الإسلاي مقارنة بالغرب - د. وائل علي المهدي أبو كروق

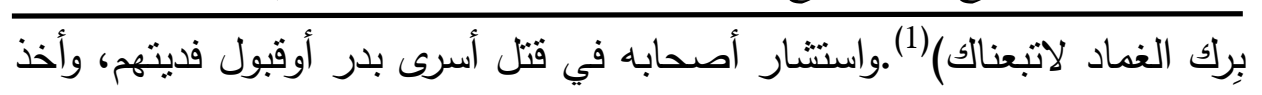

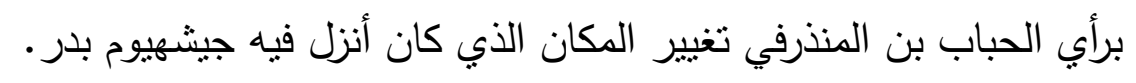

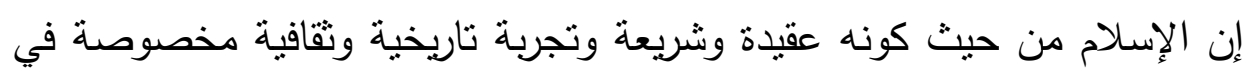

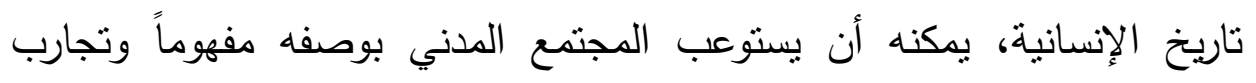
تاريخية كذلك. فعلى الرغم من استجابة المنطلقات والمسلَّمات النظرية والفكرية

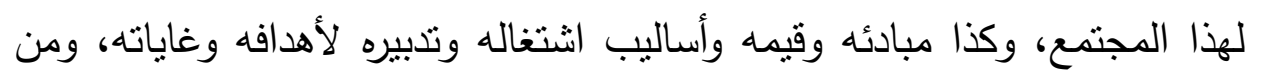

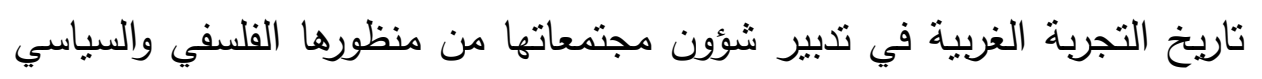

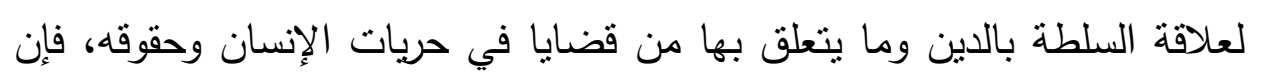

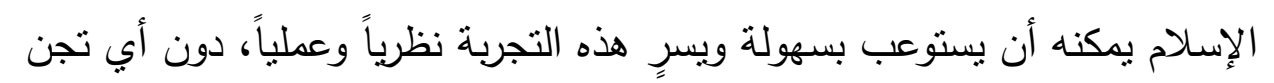
على خصوصيته العقائدية والثرعية والتاريخية، وذلك لتضمنه نفس لنس مبادئ

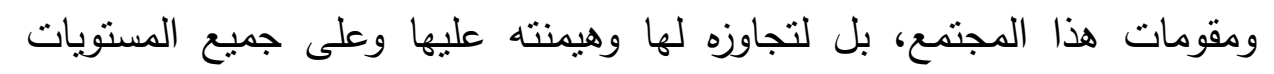

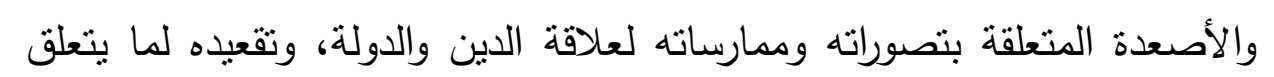
بها من أسئلة في حريات الإنسان وحقوقه، فضلاً عن أن التجربة التاريخية للإسلام

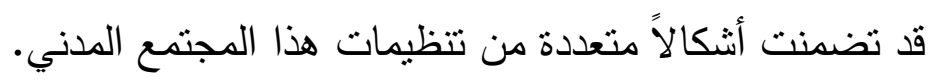

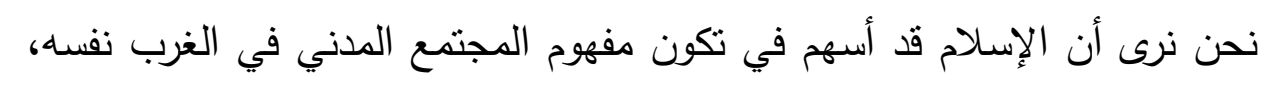

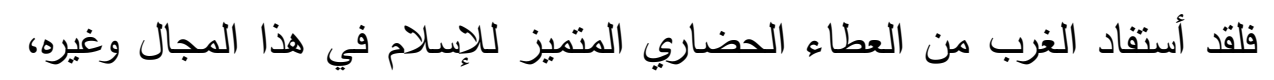

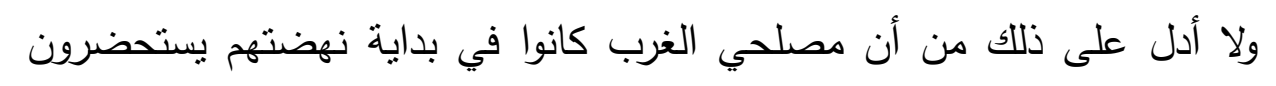

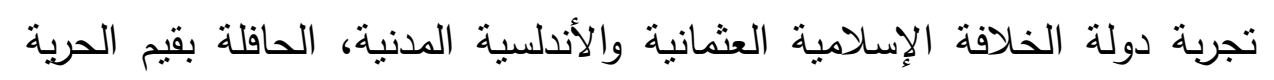

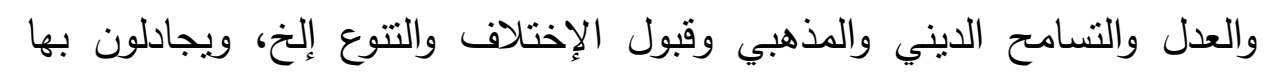
دولهم ووقائعهم الثقافية التي كانت تعرى عن هذه القيم نتيجة تقوي رجال كهنوتهم

1- أبو عبد الله أحدد بن حنبل الثشياني، المسند، مؤسسة قرطبة، مصر، د.ت. استشار النبي صلي الله علية وسلم مخرجه إلى بدر. 
وكنيستهم النصرانية بملوكهم وأباطرتهم الذينيتقون بهؤلاء ويحكمونهم بمقتضى النهى نظرية التفويض أو الحق الإلهي (1).

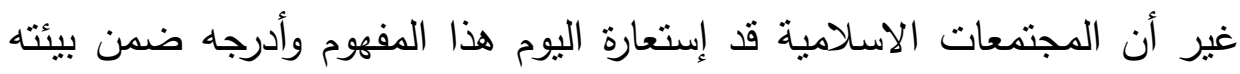

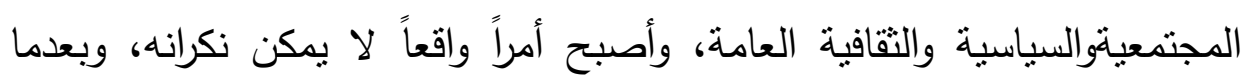

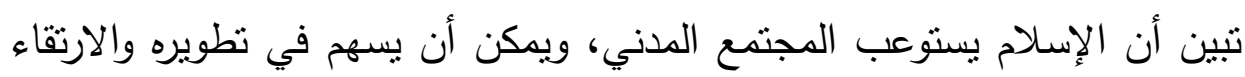

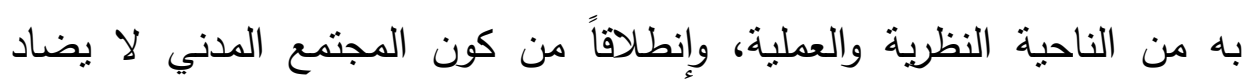

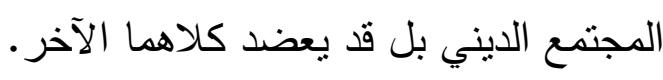

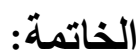

أن مصطلح المجتمع المدنيّ بشكله المحدّد، والدّعوة إلى إقامته نشأت في أوربا في

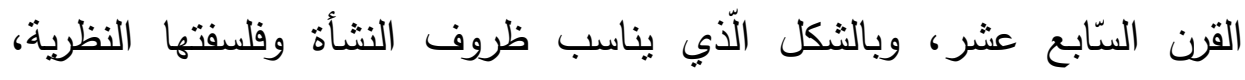

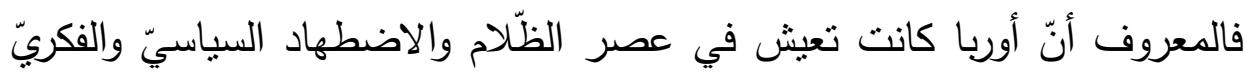

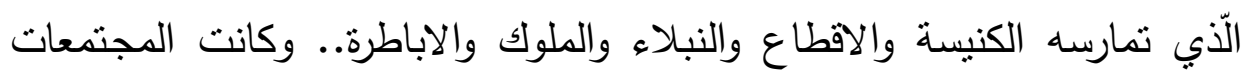

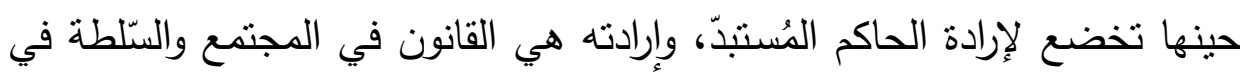

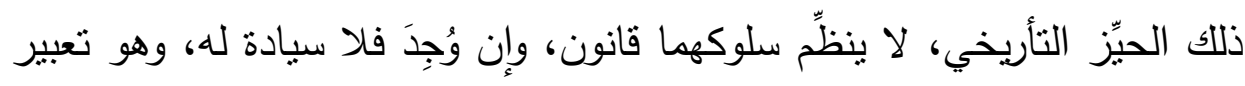

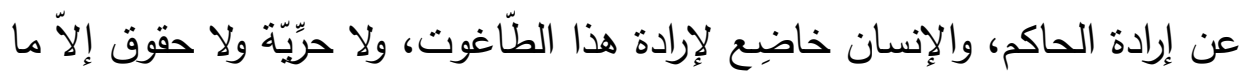

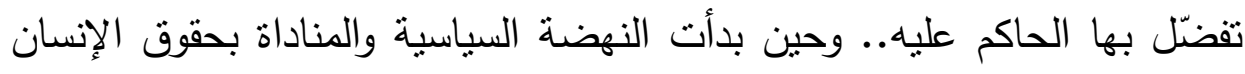
التّي في أوربا كانت تصادرها الكنيسة، وتضع حضراً على الفكر والتفكير ، ونشاط

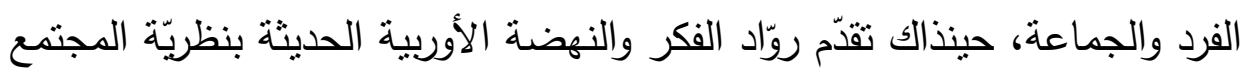
المدنيّ، ونشأ هذا المصطلح، فكتب في ذلك هوبز وروسو ولوك وهيغل وماركس، ولنئ

1- أحد صبحي منصور،الاسلام والمجتمع المدني وسلطة الحاكم، علي الرابط:htm I IVr \&http://forum.sonsofegypt.net. 
نشأة وتطور منظات الجمتع المدني في الجنمع الإسلامي مقارنة بالغرب - د. وائل علي المهدي أبو كروق

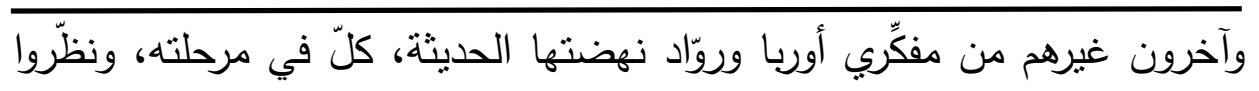
لهذا المجتمع. وأنّ الحديث عن المجتمع المدنيّ في عالمنا الإسلامي اليوم ليس هو مشروعاً

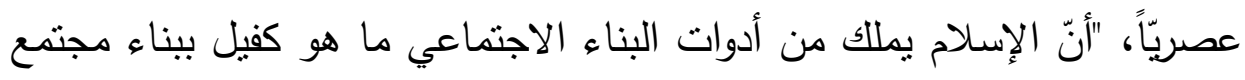

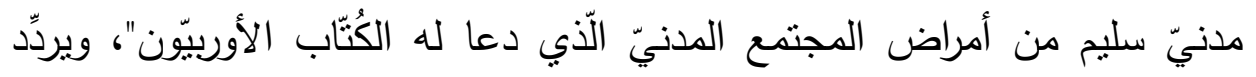

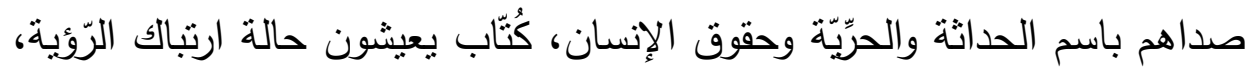

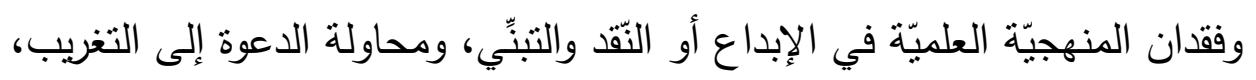
وتكرار القديم بمصطلحات حديثة.

وينبغي أن نشير هنا إلى أنّ بناء المجتمع المدنيّ هدف إنساني تسعى لتحقيقه

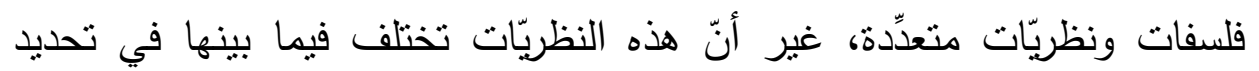

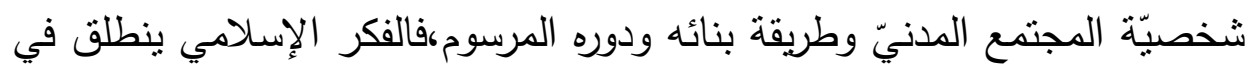

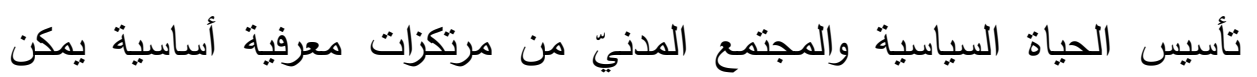

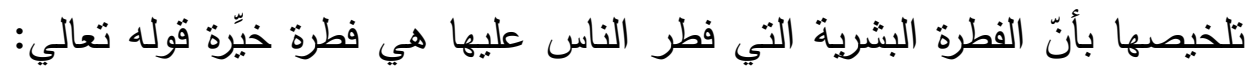

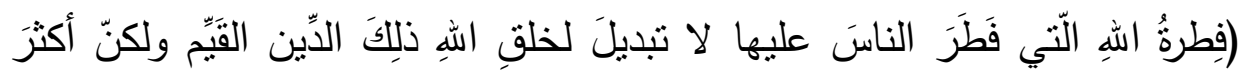

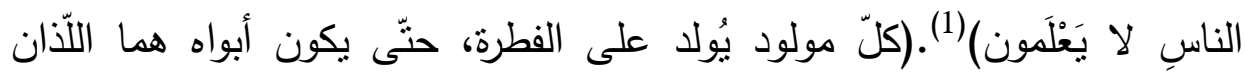

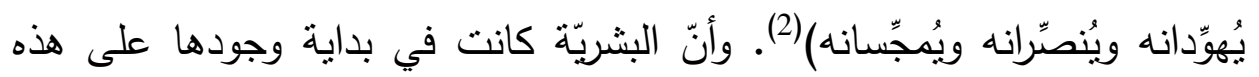

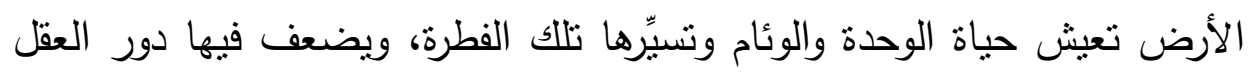

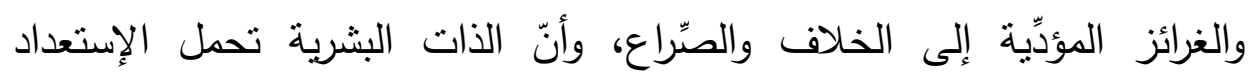

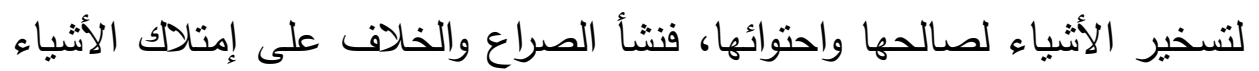

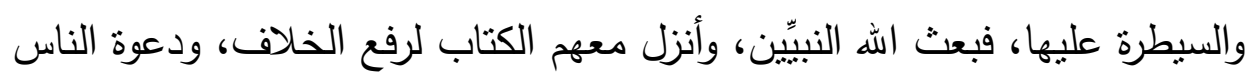

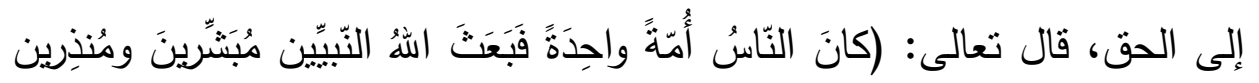

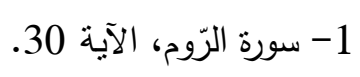

2- الطبرسي، مجمع البيان، تفسير سورة الزّوم الآية 30. 


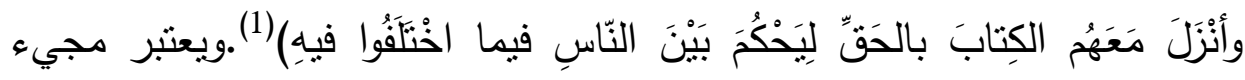
النبيين والكتاب، البداية لتأسيس المجتمع السياسي لئيس (المدنيّ) الَّي يحكمه القانون

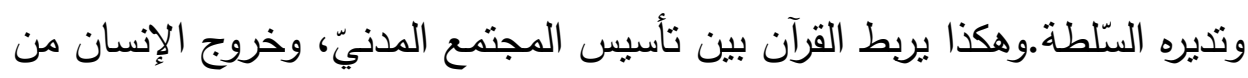

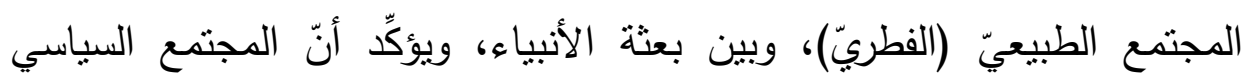

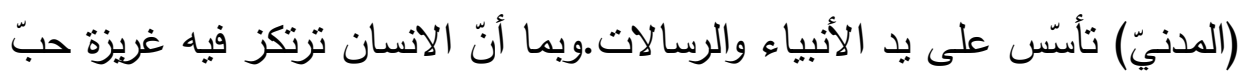

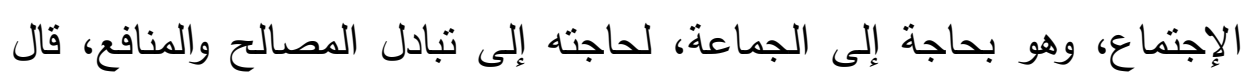

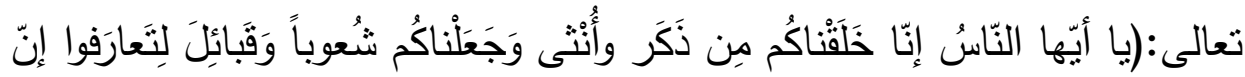

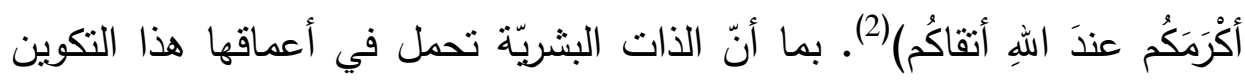

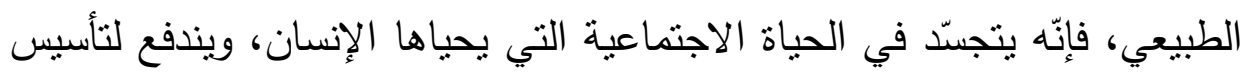

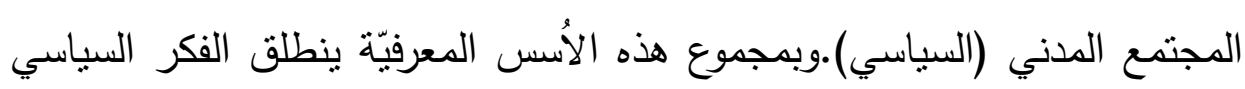
الإسلامي، وتكون مهمّة القانون والدولة هي رفع الخلاف وصيانة الفطرة بنقائها

النتائج:

إن وضع إستراتيجية لمنظمات المجتمع المدني نستدعي وضع إستخلاص

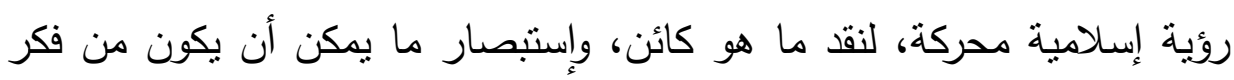

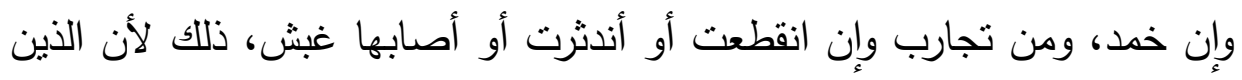

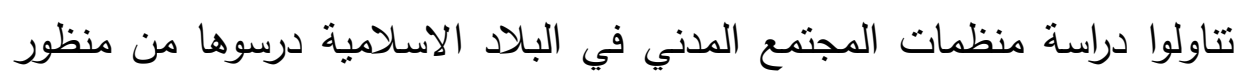

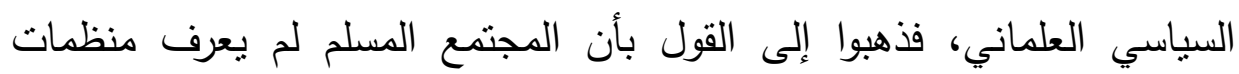

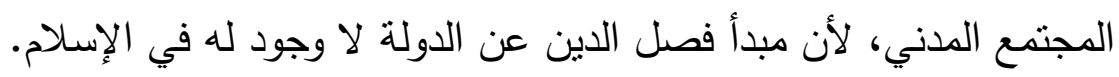

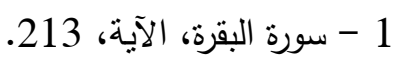

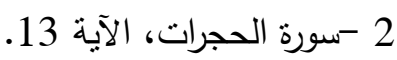


نشأة وتطور منظات الجُمتع المدني في المجتع الإسلاي مقارنة بالغرب - د. وائل علي المهدي أبو كروق

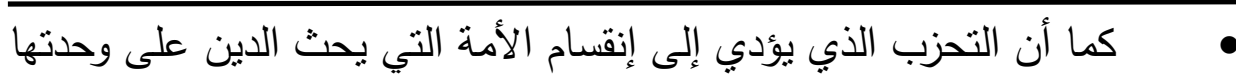

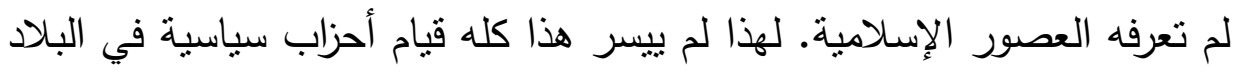
العربية كالذي حدث في الغرب إلا حديثاً بتأثير الحضارة الغربية. لهذا أغفلوا

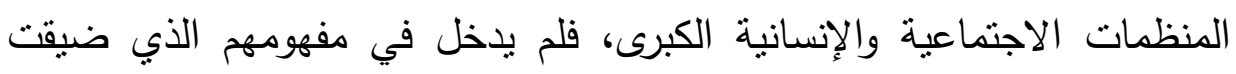

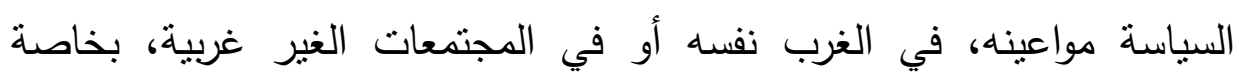
الإسلامية والعربية. الناظر في الموروث الإسلامي، فكراً وعملاً، يجد الكثير مما يساعد في لإي

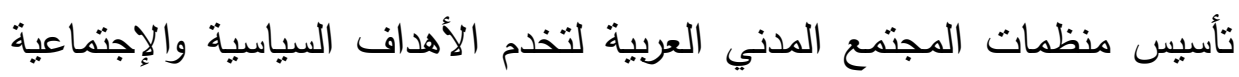
الإنسانية والاقتصادية. فالركائز الفكرية والمعيارية والوظيفية التي يمكن توظيفها

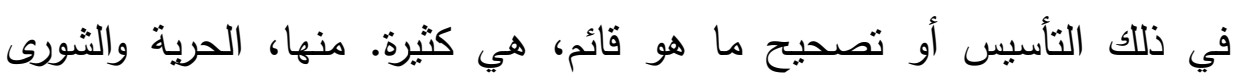
والتكافل الإجتماعي والتطوع في العمل الخيري. فاذا كانت الحرية والثنورى لم تأخذ الأشكال التي إنخذئها في أوروبا.

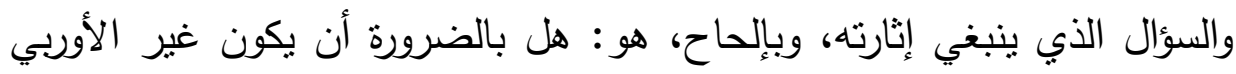

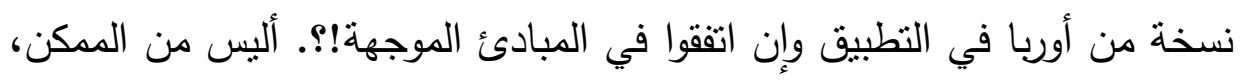

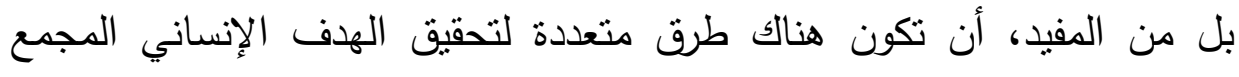

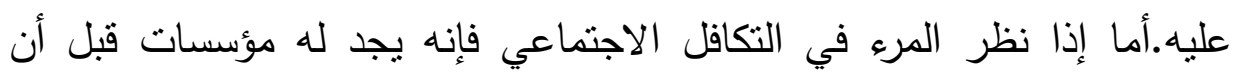

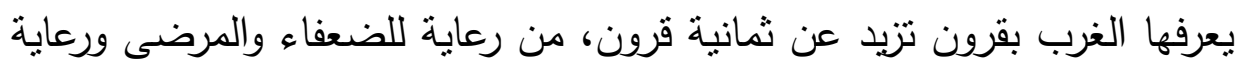
الحيوان، وكفالة طلبة العلم والقائمين على المساجد. وأخيراً إن نوظيف الباعث الديني ضرورة إلى إدراك تحقيق تلكئ الغئ الغايات.

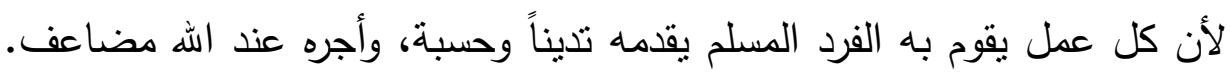
كما أن الحث على الانفاق سمة بارزة في كثير من آيات الكتاب المبين وأحاديث

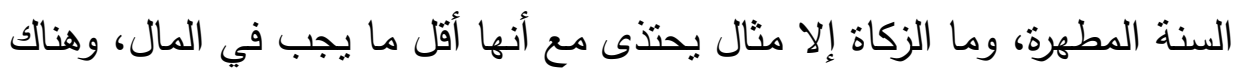
وجوه إنفاق مأجورة ربانياً كثيرة. 


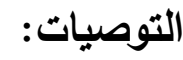

1/أن المجتمع المدني لا يثمل بني أو مؤسسات حديثة فحسب وإنما يشمل كذلك بني تقليدية كالعثيرة والقبيلة, بعبارة أخري فإن البني الاجتماعية ما قبل الدولة وبقيمها التكافلية وعصبيتها نتكل جزءاً من المجتمع المدني الذي ييقي بعد تأسيس الدولة ويجب المحافظة عليه في سياقها الايجابي.

2/ أن المجتمع الأهلي هو الأقرب لفظياً للتعريف بالمكونات أو العناصر السابقة, فهذا المجتمع الأهلي يوفر إمكانية التظيم الاجتماعي الجماعي الذاتي لأفراده بما يشير إليه ذلك من استقلالية (نسبية) عن الدولة, كما يتسم هذا المجتمع بالتتوع في المصالح والأهداف التي تسعي مؤسساته لتحقيقها, ومن ثم يستحق هذا المجتمع بله أن يسمي مجتمع التتوع والاختلاف الذي يتم حله عبر وسائل سلمية. 3/أنّ جذور المجتمع المدني في الاسلام تعود الى القيم الإسلاميّة وتعاليم الاسلام ودعواته للاعمال الخيريّة والمسؤوليّة الجماعية والمساعدات المتبادلة. فعلى سبيل المثال، تشجّع المبادئ الإسلاميّة مثنل الزّكاة والصيّدقة على تبرّع الميسورين بنسبة ودية من ثروتهم للفقراء عليه فان احياء هذه القيم يكون احياء للمجتمع المدني من المنظور الاسلامي.

2/الدعوة إلى المجتمع المدني بين المسلمين، يمكن ألا نتاقض مع مجتمعهم الديني إذا تأسست على قواعد تستتد إلى قراءة ملائمة لما جاء في العقبدة والثربعة الإسلامية والفكر السياسي والاجتماعي الإسلامي والتجربة التاريخية الإسلامية، من أجوبة علأهم قضايا المجتمع المدني، المتمثلة في إشكالات علاقة الدين بالدولة وبالحرياتوالحقوق الإنسانية، ومن دون أن تغفل النظر كذللك في واقع المجتمعات المسلمة،الذي بنبغي على المجتمع المدني أن بيتلون بألوان خصوصياتها الثقافية. 
نشآة وتطور منظات الججتع المدني في المجتع الإسلاي مقارنة بالغرب - د. وائل علي المهدي أبو كروق 3/أن الدعوة إلى مجتمع مدني في الإسلام، نسهم في تدبير التوازنات بين الدين

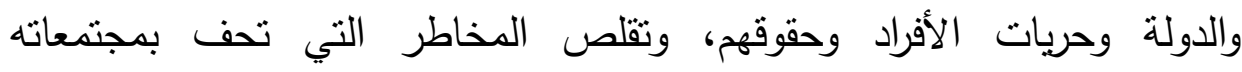

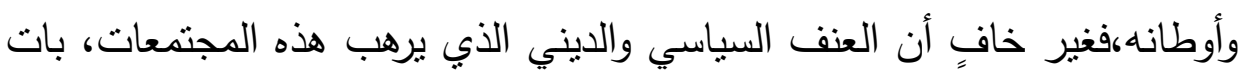

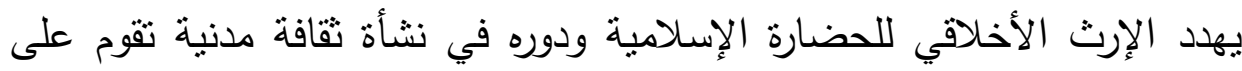
إحقاقالدق وتحرير الإنسان وتكريمه، خضوعا منها لله عز وجل الذي حرر الإني

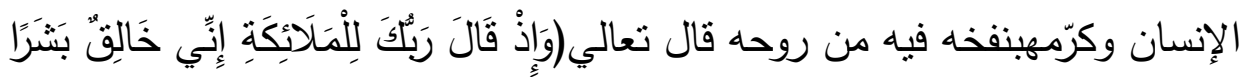

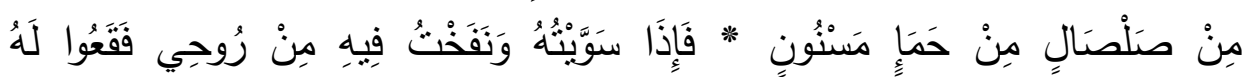

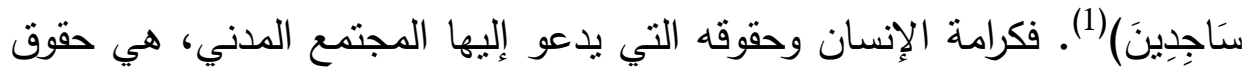
كفلها الله لجميع الناس في الإسلام. 4/ خلاصة القول إن نوظيف الدين في تحقيق الأهداف الإنسانية وتتمية المجتمع، الإسلام.

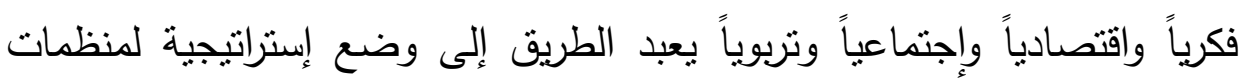

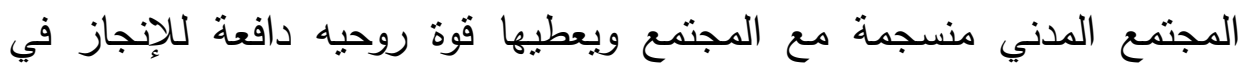
ميادين كثيرة لا تتحصر في المجال السياسي وحده.

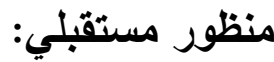

إنّ التعريف الموجَز للمجتمع المدنيّ القائم على هدي القيم الإسلامية يُوضِّح لنا

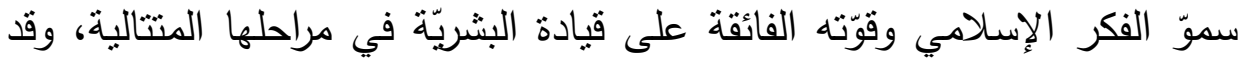
ظهر في تاريخ المجتمعات المسلمة العديد من التنظيمات التظوعية، التي لا لا لتانيل تستهف الربح، والتي تمنعت بقدر من الاستقال عن الدولة، والتي يمكن اعتبارها نواه لمؤسسات المجتمع المدني الاسلامى واتفقت مع واقع المجتمعات المسلمة في ذللك الزمان والمكان،ويمكن تطويرها بما يتقق مع الواقع المعاصر لهذه

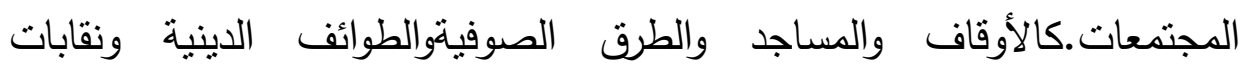

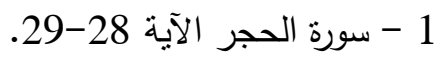


الحرفيين، فيجدر بنا نحن المسلمين أن نوجِّه الدعوة إلى العالَّ لكي يتّخذ من الإسلام ديناً ودولةً وحضارة.

فليس أمام البشريّة من مُنقِذ غير الإسلام، وسنكتشف أجيال البشريّة القادمة عظمة هذا الدِّين الإلهيّ عندما بسود العلم والعقل. وعندها بنطبق قول الله الحق:(وَََقَّ

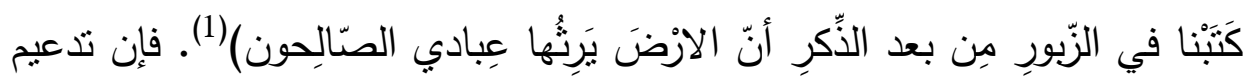
مفاهيم المجتمع المدني ليس جها علمانيا وإنما هو في الحقيقة خدمة للإسلام الصحيح الذي ظلمه التطرف والإرهاب.

قائمة المصادر والمراجع أولاً: القرآن الكريم: المها:

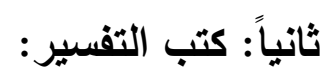
1/ أبو عبد الله أحمد بن حنبل الثبياني، المسند، مؤسسة قرطبة، مصر ، د.ت. 2/ الطبرسي، مجمع البيان.

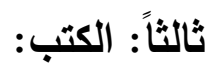

1/ أبوالأعلى المودودي، نظرية الإسلام وهديه في السياسة والقانون والدستور، دار الفكر ، دمشق، 1997م.

2/ أحمد حسين حسن، الجماعات السياسية الإسلامية والمجتمع المدني،القاهرة، الدار الثقافية للنشر، 2000م.

3/ أحمد فؤاد عبد الجواد عبد المجيد، البيعة عند مفكري أهل السنة والعقد الاجتماعي في الفكر الإسلامي الحديث، دراسة مقارنة في الفلسفة السياسية، دار قباء، القاهرة، 1999م.

1- - سورة الانبياء، الآية 105. 


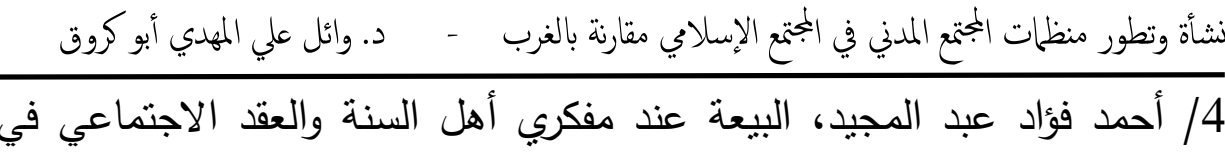
الفكر الإسلامي الحديث، دراسة مقارنة في الفلسفة السياسية، دار قباء، القاهرة، 1998

5/ الإمام محمد عبده، الأعمال الكاملة، تحقيق وتقديم: محمد عمارة، دار

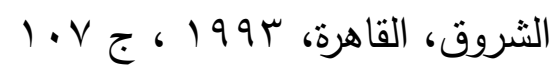

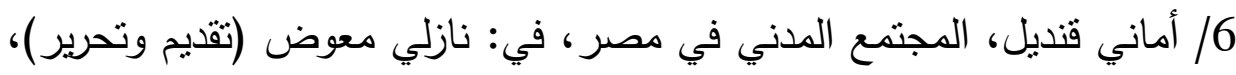

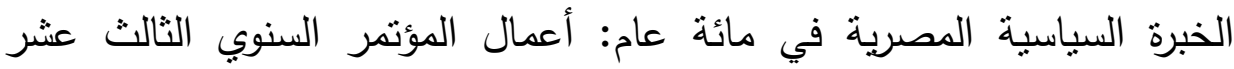
للبحوث السياسية 4-6 ديسمبر 1999، القاهرة: مركز البحوث والدراسات السياسية بكلية الاقتصاد والعلوم السياسية، 2001م.

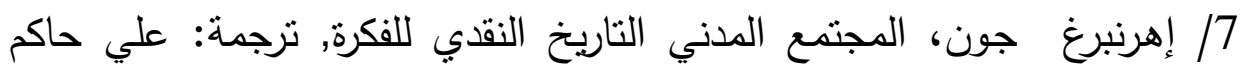

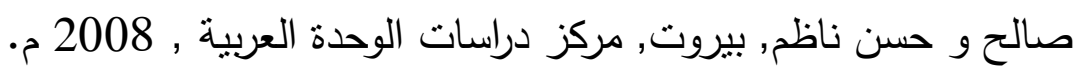

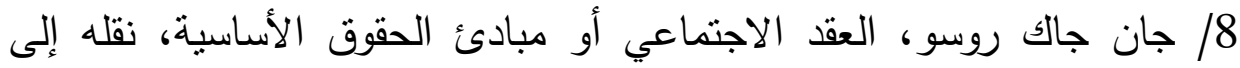

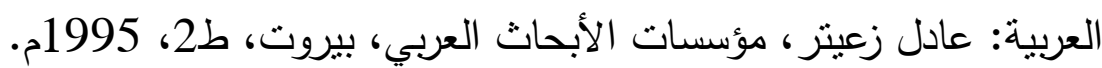

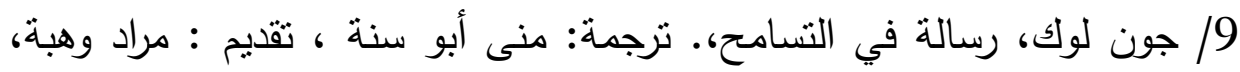

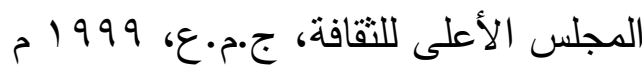

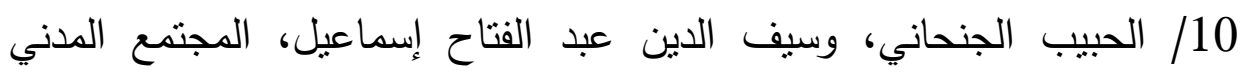

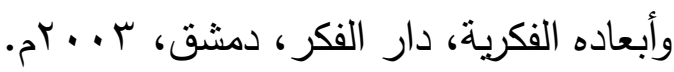

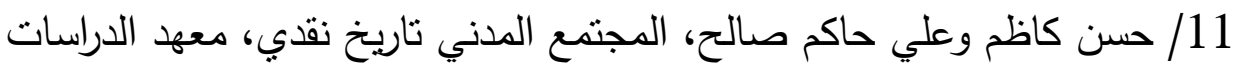

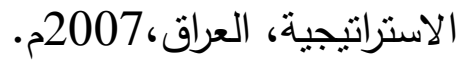
12/ سعد الدين إبراهيم، (مشرف عام)، دور وسائل الإعلام العربية في دعم تقافة

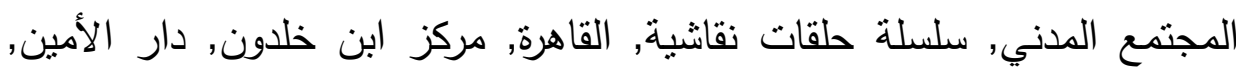
1997 
13/ سفر الحوالي، العلمانية: نثأتها ونطورها وتأثيرها على الحياة الإسلامية المعاصرة، دار الهجرة، د.ت. 14/ سيد قطب، معالم في الطريق، عرض ورؤية فتحي الثقاقي، دار الثروق،

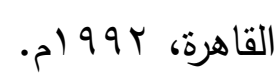
15/ عبد الغفار شكر ، المجتمع الأهلي ودوره في بناء الديمقراطية، سلسلة حوارات

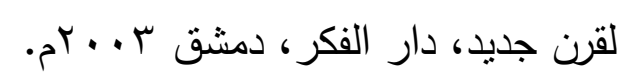

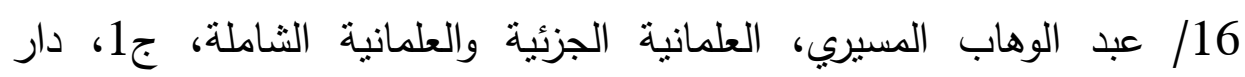
الثروق، 2002م.

17/ علي الدين هلال و نيفين مسعد، النظم السياسية العربية: قضايا الاستمرار

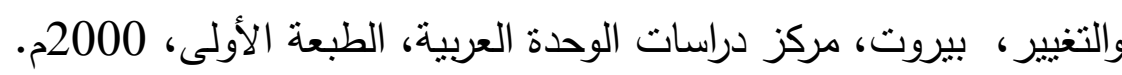

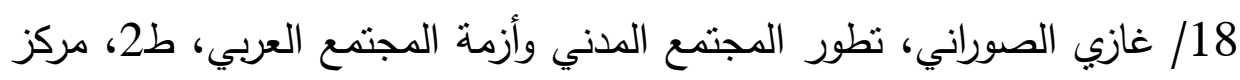

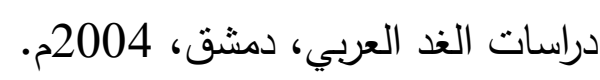

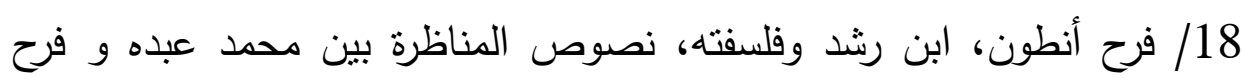

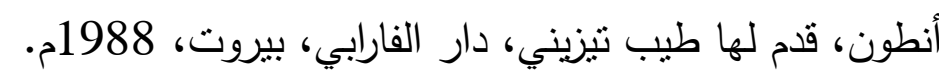

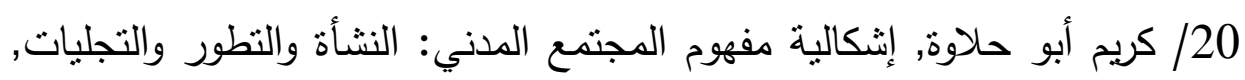

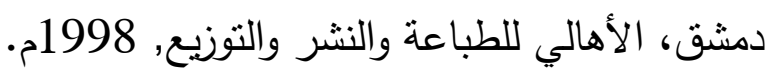

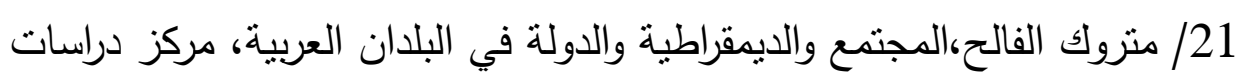

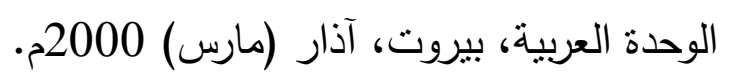

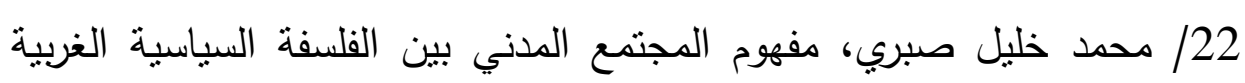

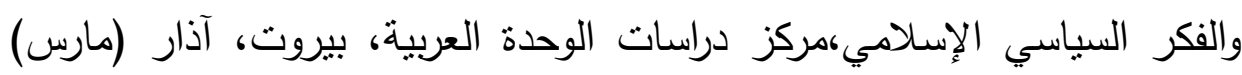
2000 23/2300 محمد عمارة، الدولة الإسلامية بين العلمانية والسلطة الدينية، دار الثروق،

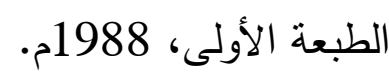


نشأة وتطور منظات الجمتع المدني في الجنمع الإسلاي مقارنة بالغرب - د. وائل علي المهدي أبو كوق

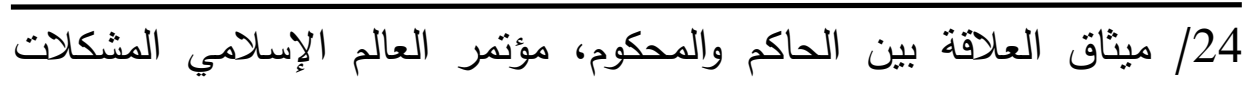

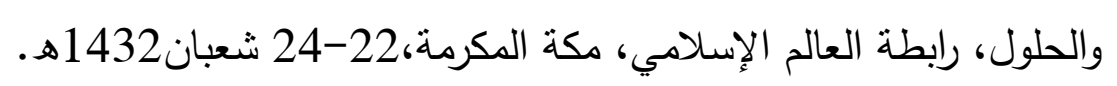

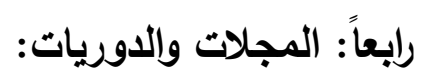

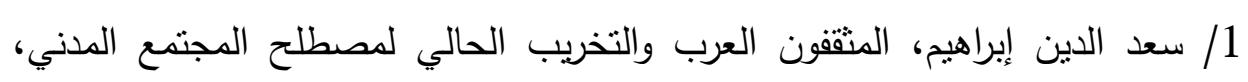

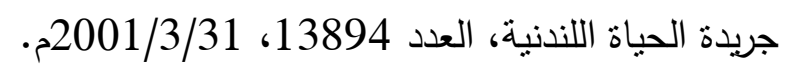

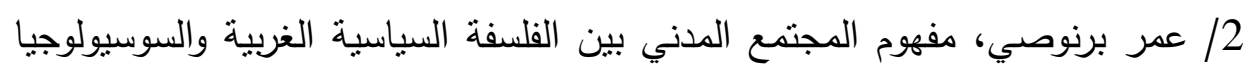

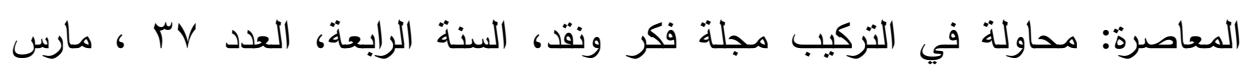
2000م. 3 متعب مناف، لماذا المجتمع الدنني، مجلة الحكمة، دار الحكمة، بغداد، العدد 361، 2004

4/ محمد الغيلاني، محنة المجتمع المدني: مفارقات الوظيفة ورهانات الاستقلالية، دفاتر

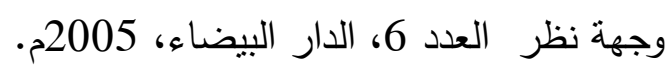

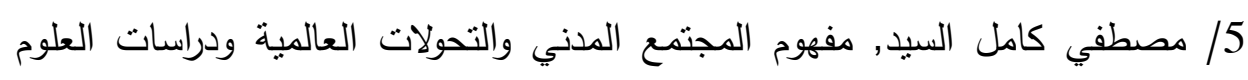

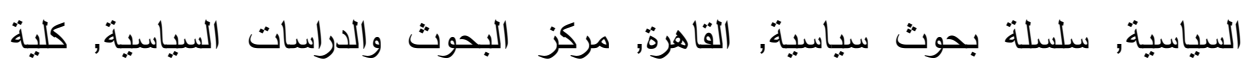

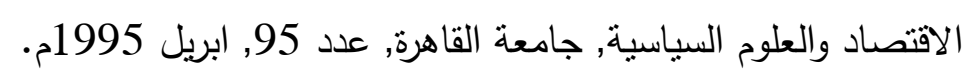

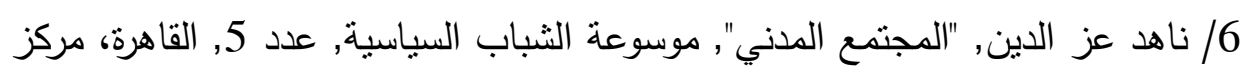

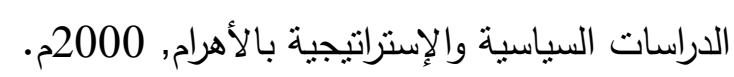

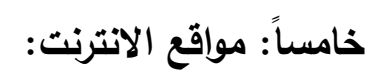
1/ أحمد صبحي منصور، الاسلام والمجتمع المدني و سلطة الحاكم، علي الرابط: .htm ) TVr $\leqslant$ http://forum.sonsofegypt.net/t 2/ أرشيف الماركسيين على شبكة الإنترنت والذي يورد مقتطفات مطولة من كتابات جرامشي ونبذة عن حياته وتحليلاً لآرائه: الإنرن

http://www.marxists.org/archive/gramsci/index.htm

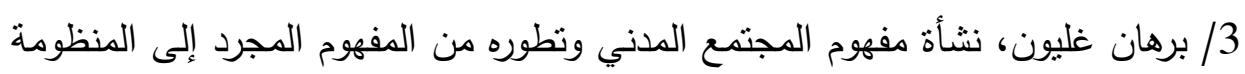

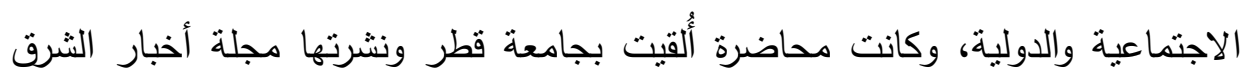


على ثلاثة حلقات في أعدادها بتاريخ 19، 20، 21 مارس 2002، وهي منشورة على الرابط النالي على شبكة الإنترنت:/articles.html19/03/2002http://www.thisissyria.net 4/جون مولينو، الماركسية والحزب، والذي جعل عنوان الفصل السادس منه والذي عرض فيه لفكر جرامشي: جرامثي والأمير الحديث، والكتاب منشور على موقع مركز الدراسات الاشتراكية على شبكة الإنترنت على الرابط التالي: .htm6http://www.mdar.org/tragm/mp/part /5/ عبد الهه موسى، المجتمع الأهلي: المشروع المغيب ودور السلطة، مجلة النبأ، العددين 30-31، ذو القعدة-ذو الحجة 1419، على موقع المجلة على شبكة الإنتزنت على الرابط التالي: /mojtamaa.htm31-30http://www.annabaa.org/nba 6/ عبد المجيد الأنصاري، جذور ومظاهر المجتمع المدني في الفكر والمجتمع http://www.iraqcenter.net الإسلامي، علي الرابط:

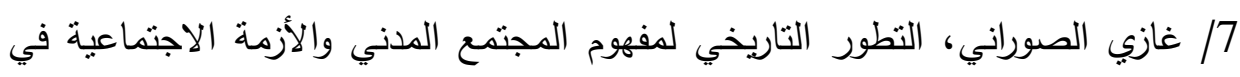
بلدان الوطن العربي وآفاق المستقبل، والمنشور على شبكة الإنترنت على الرابط التالي: 9489http://www.rezgar.com/debat/word.art.asp?aid= 8/ هثام جعفر، العمل الأهلي: رؤية إسلامية، على موقع الإسلام على الإنترنت أيضًا على الرابط: /article2000/02http://www.islamonline.net/Arabic/contemporary/

.shtml57

9/9 وجيه كوثراني،المجتمع المدني والمجتمع الأهلي في حضارتين: الغربية والإسلامية، مجلة التسامح، العدد الثامن، منشور حاليا على موقع المجلة علي

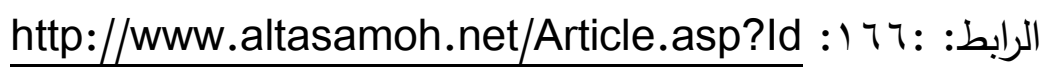




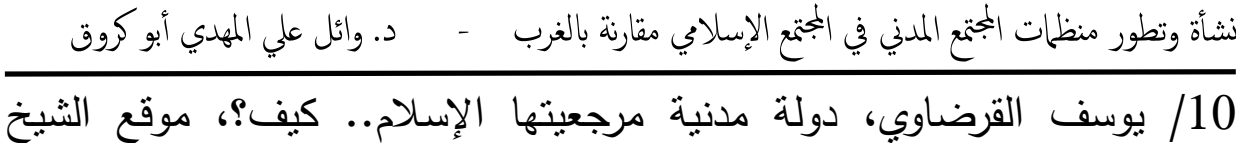

يوسف القرضاوي، علي الرابط: http://www.qaradawi.net 